\title{
Novel Catalytic Ceramic Conversion Treatment of Ti6Al4V for Improved Tribological and Antibacterial Properties for Biomedical Applications
}

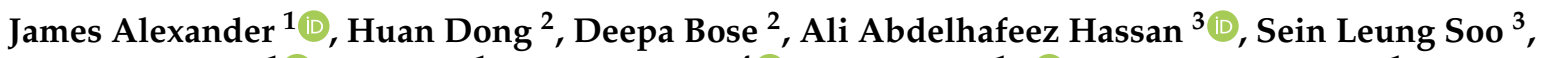 \\ Zhenxue Zhang ${ }^{1}{ }^{\mathbb{D}}$, Xiao Tao ${ }^{1}$, Sarah Kuehne ${ }^{4} \mathbb{1}$, Xiaoying $\mathrm{Li}^{1, *}{ }^{1}$ and Hanshan Dong ${ }^{1}$ \\ 1 School of Metallurgy and Materials, University of Birmingham, Birmingham B15 2TT, UK; \\ JXA387@student.bham.ac.uk (J.A.); z.zhang.1@bham.ac.uk (Z.Z.);X.Tao@bham.ac.uk (X.T.); \\ h.dong.20@bham.ac.uk (H.D.) \\ 2 Queen Elizabeth Hospital, Birmingham B15 2WB, UK; huan.dong@nhs.net (H.D.); \\ deepabose@yahoo.com (D.B.) \\ 3 School of Engineering, University of Birmingham, Birmingham B15 2TT, UK; \\ A.M.AbdelhafeezHassan@bham.ac.uk (A.A.H.); s.l.soo@bham.ac.uk (S.L.S.) \\ 4 School of Dentistry, University of Birmingham, Birmingham B5 7EG, UK; S.A.Kuehne@bham.ac.uk \\ * Correspondence: x.li.1@bham.ac.uk
}

Citation: Alexander, J.; Dong, H.; Bose, D.; Hassan, A.A.; Soo, S.L.; Zhang, Z.; Tao, X.; Kuehne, S.; Li, X.; Dong, H. Novel Catalytic Ceramic Conversion Treatment of Ti6Al4V for Improved Tribological and Antibacterial Properties for Biomedical Applications. Materials 2021, 14, 6554. https://doi.org/ $10.3390 /$ ma14216554

Academic Editor:

Radu Robert Piticescu

Received: 14 October 2021

Accepted: 28 October 2021

Published: 1 November 2021

Publisher's Note: MDPI stays neutral with regard to jurisdictional claims in published maps and institutional affiliations.

Copyright: (C) 2021 by the authors. Licensee MDPI, Basel, Switzerland. This article is an open access article distributed under the terms and conditions of the Creative Commons Attribution (CC BY) license (https:/ / creativecommons.org/licenses/by/ $4.0 /)$.

\begin{abstract}
Titanium oxide layers were produced via a novel catalytic ceramic conversion treatment (CCCT, C3T) on Ti-6Al-4V. This CCCT process is carried out by applying thin catalytic films of silver and palladium onto the substrate before an already established traditional ceramic conversion treatment (CCT, C2T) is carried out. The layers were characterised using scanning electron microscopy, X-ray diffraction, transmission electron microscopy; surface micro-hardness and reciprocating tribological performance was assessed; antibacterial performance was also assessed with $S$. aureus. This CCCT has been shown to increase the oxide thickness from $\sim 5$ to $\sim 100 \mu \mathrm{m}$, with the production of an aluminium rich layer and agglomerates of silver and palladium oxide surrounded by vanadium oxide at the surface. The wear factor was significantly reduced from $\sim 393$ to $\sim 5 \mathrm{~m}^{3} / \mathrm{N} \cdot \mathrm{m}$, and a significant reduction in the number of colony-forming units per $\mathrm{ml}$ of Staphylococcus aureus on the CCCT surfaces was observed. The potential of the novel C3T treatment has been demonstrated by comparing the performance of C3T treated and untreated Ti6Al4V fixation pins through inserting into simulated bone materials.
\end{abstract}

Keywords: ceramic conversion; Titanium oxide; surface hardening of Ti alloys; biomechanical properties; Ti fixation pins; antibacterial behaviour

\section{Introduction}

Due to their high strength-to-weight ratio and superior corrosion resistance, titanium alloys have been adopted for a wide range of applications. Especially within the aerospace industry for which Ti-6Al-4V was the first developed workhorse. Since then, it has been shown to have attractive and beneficial effects within the biomedical field in terms of satisfactory biocompatibility and desirable osseointegration for orthopaedic and dental implants. In addition to this, its low elastic modulus aids in reducing the stress-shielding phenomenon and therefore could reduce the number of failures due to aseptic loosening of load-bearing prosthesis [1-3].

However, titanium (Ti) and its alloys have poor tribological properties as they are prone to galling. This is mainly because of their low hardness, ease of plastic deformation, and high reactivity, thus causing strong adhesion and even seizure. To make matters worse, the poor wear properties of Ti leads to the formation of Ti wear debris from contacting surfaces. For example, galvanic corrosion and fretting wear occurred at the Ti stem/CoCr head taper connection of modular designed hip prosthesis when the naturally formed very 
thin $\mathrm{TiO}_{2}$ film was removed by fretting [4]. Wear debris can also be produced during the insertion of the fixture of dental implants [5] and self-drilling fixation pins for external fracture fixation [6].

Metal debris is the main reason for the release of titanium ions due to the dissolution of wear particles. This may lead to tissue discolouration and/or elicit an adverse inflammatory response, which will cause inflammation, peri-implantitis and eventually aseptic implant loosening $[7,8]$. In addition to these local implications, the release of ions into the surrounding tissue can result in systemic implications. This is because if the particles/ions diffuse through the tissue, they can get distributed through the lymphatic system, and therefore accumulate in the liver and spleen $[9,10]$. Thus, how to improve the tribological properties of Ti implants and reduce wear debris induced metal ion release presents a major challenge to the performance and longevity of Ti implants. To this end, great efforts have been made to coat Ti implants with bio-inert hard ceramic coatings (such as CrN \& DLC) or bio-active coatings (such as HA). However, spallation of coatings due to poor interfacial bonding and low load supporting of the soft Ti substrate has cast a shadow on the successful use of coatings for load supporting Ti implants.

A recently developed ceramic conversion treatment (C2T) can address the concerns over thin coatings by in-situ converting a Ti surface into a wear resistant and bio-active $\mathrm{TiO}_{2}$ ceramic layer via thermal oxidation, which is supported by an oxygen diffusion hardened subsurface [11] and has shown some promise for improving the wear resistance of Ti fixation pins [12]. The C2T normally takes about $80-100 \mathrm{~h}$ at $600-620^{\circ} \mathrm{C}$ to produce a surface oxide layer approximately 2-3 microns with good bonding to the substrate. This not only leads to high energy consumption and low production efficiency, but also causes the loss of bulk material strength due to over aging. In addition, it is impossible to produce a thick (>4 microns) $\mathrm{TiO}_{2}$ layer without causing spallation of the oxide layer due to poor bonding.

Another major challenge for premature implant failure is due to implant-associated infection [13]. Although there is not much literature published on the true cost of these infections, they result in the need for revision surgery, which not only reduces the patient's quality of life but also puts a major financial strain on the NHS. Both surface topography and chemistry influence the response of host cell and bacterial adhesion to implant surfaces. One of the methods to reduce the amount of bacterial adhesion is to alter the surface chemistry by applying antimicrobial substances to said surface. A well-documented antimicrobial substance is silver, which in the presence of water/body fluids releases silver cations $(\mathrm{Ag}+)$. This $\mathrm{Ag}+$ has an affinity for sulphydryl groups and proteins on cell membranes. Ag+ is then able to alter bacterial cell membranes thus influencing permeability and causing intracellular uptake of $\mathrm{Ag}+$. Then once inside the cells, the $\mathrm{Ag}+$ can interact with subcellular components and therefore impair cellular metabolism and replication [13-15]. However, the major concern over Ag-containing coatings is failure of the coating, fast leaching of Ag ions, and the resulting toxicity [16]. Although C2T surfaces demonstrate a certain level of antimicrobial capability, it should be noted that the efficacy is most probably too low to effectively combat post-implantation infection.

To this end, this paper reports, for the first time, a novel surface engineering technology to generate a thick $\mathrm{TiO}_{2}$ oxide layer with both high wear resistance and antimicrobial efficacy within a short period of time based on catalytic ceramic conversion treatment (C3T) by pre-depositing a thin catalysing layer consisting of $\mathrm{Ag}$ and Pd prior to ceramic conversion treatment. The surface cases formed on Ti6Al4V by C3T were fully characterised, the wear and antibacterial efficacy evaluated, and the potential of the novel C3T treatment has been demonstrated by comparing the performance of C3T treated and untreated Ti6Al4V fixation pins through insertion into simulated bone materials. Based on the results, possible mechanisms of the catalytic effect of $\mathrm{Ag} / \mathrm{Pd}$ on the fast growth of a good quality surface oxide layer is discussed. This reported new study, from a scientific point-of-view, advanced scientific understanding of the mechanism involved and, from technological point of view, paves the way for biomedical applications. 


\section{Materials and Methods}

\subsection{Coupons and Fixation Pins}

Ti-6Al-4V coupon samples with a thickness of $4 \mathrm{~mm}$ were prepared from a hot-rolled and annealed bar (supplied by IMI Titanium Ltd., Birmingham, UK) of one inch in diameter. The coupon samples were ceramic conversion treated and used for microstructural and property characterisation. Optimised conditions derived from the characterisation of treated coupon samples was selected to treat the commercial Ti6Al4V titanium alloy selfdrilling/self-tapping pins (Apex 5018-6-150S, Stryker, MI, USA). The diameter of the pin, total length and thread length were 5,150 and $50 \mathrm{~mm}$, respectively.

\subsection{Coatings of Catalytic Layer and Ceramic Conversion Treatments}

A catalytic layer of Ag, Pd and Ag + Pd, was coated on Ti64 coupons via a Closed Field Unbalanced Magnetron Sputter Ion Plating (CFUMSIP) system (Teer Coatings, Droitwich, UK). The coatings were carried out in an argon environment with silver, and/or palladium targets, at a current of $1 \mathrm{~A}$ and a bias voltage of $40 \mathrm{~V}$. Pulsed mode was utilised at a frequency of $50 \mathrm{kHz}$ and pulse width of $1500 \mathrm{~ns}$. To enable a stable plasma the current was ramped up from 0.3 to $1 \mathrm{~A}$ in $30 \mathrm{~s}$. The coating processing time was $4 \mathrm{~min}$, which yields a deposition coating layer of $\approx 330 \mathrm{~nm}$ on the surfaces of the coupons and the pins. The respective coverage of the deposited $\mathrm{Ag}, \mathrm{Pd}$ and $\mathrm{Ag} / \mathrm{Pd}$ on the surfaces of the coupons were observed after the coating processes and it was revealed that the deposited layers were homogeneously distributed on the surfaces.

Based on a patented [17] treatment, Ceramic Conversion Treatment, CCT or C2T was carried out on coupon samples with and without catalytic coatings. This converts the titanium surface into a ceramic oxide layer and introduces oxygen into the subsurface to form an oxygen solid solution hardened diffusion case. While the pre-coating layer acts as a catalyst, accelerating the surface ceramic conversion process, named as Catalytic Ceramic Conversion Treatment, CCCT or C3T.

A series of ceramic conversion treatments were carried out to investigate the optimal conditions for producing a surface layer with improved wear resistance and antimicrobial properties. Firstly, samples with and without an $\mathrm{Ag} / \mathrm{Pd}$ deposition layer were treated at temperatures of 580,620 and $660^{\circ} \mathrm{C}$ for $80 \mathrm{~h}$. After characterisation of the $80 \mathrm{~h}$ treated samples in terms of the oxide layer quality, thickness and adhesion to the substrate, $660{ }^{\circ} \mathrm{C}$ was selected for a series of treatment durations ranging from 1 to $80 \mathrm{~h}$. Characterisation on these samples revealed a good quality layer for the $5 \mathrm{~h}$ treated samples in terms of surface hardness, thickness and interfacial bonding. Further investigations were designed to have individual catalyst coatings of $\mathrm{Ag}$ or Pd pre-deposited on the coupons for ceramic conversion treatment of $660{ }^{\circ} \mathrm{C} / 5 \mathrm{~h}$. A controlled atmosphere containing $20 \%$ oxygen and $80 \%$ nitrogen, at a pressure under $100 \mathrm{kPa}$ were constants for all the treatments. Table 1 details the sample codes, denoted in terms of the pre-coating, treatment temperature, and duration etc. Based on the microstructure characterisation and mechanical property evaluation of the coupons, the C3T660-5 with a catalytic layer of $\mathrm{Ag}+\mathrm{Pd}$ deposition was selected to treat the fixation pins.

\subsection{Microstructure Characterisation of Treated Coupons and Pins}

Treated coupon samples were cut and hot mounted with conductive bakelite. The samples were ground to 1200 grit size with SiC paper and then polished using 6 and then $3 \mu \mathrm{m}$ diamond suspension, and finally activated colloidal silica suspension. The metallographic microstructures of the samples were revealed using Kroll's reagent. Surface morphology, layer structure and composition of the coupons were characterised using a JEOL 7000F SEM (Tokyo, Japan) equipped with Energy-dispersive X-ray spectrometer (EDX; Oxford Instruments Inca, Oxford, UK). The surface layer thickness was measured using Image J on SEM images and an average of at least 5 times measurements was taken as the layer thickness. The tip shapes and surface morphology of the pins were optically observed. 
The phase composition was analysed using an X-ray diffraction instrument (XRD, D8 Advanced, Bruker, MA, USA), with a Cu source $(\mathrm{K} \alpha=0.154 \mathrm{~nm})$. Further detailed surface layer microstructure and phase composition were analysed for the C3T660-20PdAg sample by transmission electron microscope (TEM). The TEM specimens were prepared perpendicular to the surface by using focused ion beam (FIB, Quanta 3D, FEI company, Oregon, USA) following the standard steps of Pt deposition, bulk-out, u-cut, lift out, mounting, thinning, and cleaning. The microstructure was examined using an electron microscope (LaB6, 200 kV) (2100, Jeol, Tokyo, Japan). High angle annular dark field (HAADF) imaging and Energy-dispersive X-ray spectroscopy (Oxford ISIS EDX, Oxford, UK) analysis were performed using scanning TEM (STEM) mode with a Philips Tecnai F20 instrument (FEG, 200 kV) (Philips Electron Optics, OR, USA).

Table 1. Treatment conditions for the coded samples.

\begin{tabular}{ccc}
\hline Code & Catalytic Layer & Treatment, T-t $\left({ }^{\circ} \mathbf{C}-\mathbf{h}\right)$ \\
\hline Unt & - & - \\
C2T580-80 & No & $580-80$ \\
C2T620-80 & No & $620-80$ \\
C2T660-80 & No & $660-80$ \\
C3T580-80PdAg & Pd + Ag & $580-80$ \\
C3T620-80PdAg & Pd + Ag & $620-80$ \\
C3T660-80PdAg & Pd +Ag & $660-80$ \\
C3T660-hPdAg & Pd + Ag & $660-1,5,10,20,40,60,80$ \\
C2T & No & $660-5$ \\
C3TAg & Ag & $660-5$ \\
C3TPd & Pd & $660-5$ \\
\hline
\end{tabular}

\subsection{Mechanical Property Evaluation}

Microhardness of the coupons were measured using a MKV-H1 hardness tester (Mitutoyo, Kanagawa, Japan) with a Vickers indenter under the load of 25 and $50 \mathrm{~g}$ and the hardness value is an average of five measurements with the standard deviation as the error bars. The tribological performance was measured using a TE79 tribometer (Phoenix Tribology Ltd, Berkshire, UK) with an $8 \mathrm{~mm}$ dimeter tungsten carbide counterpart. The reciprocating distance was $5 \mathrm{~mm}$ for 1000 cycles, equating to a total $5 \mathrm{~m}$ sliding distance. A lighter, $15 \mathrm{~N}$, and heavy, $50 \mathrm{~N}$, load was used to evaluate the tribological properties of untreated and ceramic conversion treated Ti-6Al-4V coupons. The cross-sectional areas of the wear tracks were measured using an Ambios XP-Plus 200 Stylus Profilometer (Ambios Technology, CA, USA), and subsequently, wear volume was calculated by multiplying the cross-sectional area by the length of the wear track. The morphology of the wear tracks was SEM observed.

A comparison of biomechanical properties of Unt and C3T660-5PdAg treated Ti6Al4V pins were evaluated by insertion tests using a cortical bone-simulating material SAWBONES ${ }^{\circledR}$ (Europe AB, Malmö, Sweden) that was delivered as blocks measuring $30 \mathrm{~mm} \times 17 \mathrm{~mm} \times 10 \mathrm{~mm}$. These blocks were used to simulate mechanical pin insertion in actual bone. FX5 machining centre (an industrial drilling machine, Matsuura Machinery Ltd, Coalville, UK) was employed to conduct the insertion tests under a constant feed rate of $70 \mathrm{~mm} / \mathrm{min}$ and rotational speed of $360 \mathrm{rpm}$ for an insertion depth of $25 \mathrm{~mm}$ without pre-drilling through the bone block. The applied axial force needed to achieve the steady insertion speed was measured by a Rotating Dynamometer (Type 9123B) (Kistler Instruments Ltd, Hampshire, UK) connected to a PC equipped with Dynoware program (Kistler Instruments Ltd, Hampshire, UK) for force signal acquisition and conditioning. The insertion performance was evaluated by contrasting the maximum axial insertion force in each test as well a post-insertion observation of the wear of treated and untreated pins using Toolmakers optical microscopy having maximum magnification of $400 \times$ and fitted with a camera for micrographs capturing. 


\subsection{Antibacterial Testing}

Antibacterial performance was assessed of Unt, C2T620-80 and C3T660-20PdAg Ti-6Al-4V coupons ( $\mathrm{n}=3$ ) using a methodology based on the Miles and Misra method [18]. Single colonies of gram-positive Staphylococcus aureus (S. aureus) (NCTC 6571) were serially diluted in trypton soya broth (TSB) down to $10^{4}$ from $10^{9}$ cells $/ \mathrm{mL}$. Each sample was inoculated with $20 \mu \mathrm{L}$ of this solution and then incubated for $6 \mathrm{~h}$ before dilution in $10 \mathrm{~mL}$ of phosphate buffered saline (PBS) and vortexing to dislodge the surface adhered bacteria. Serial dilutions to dilute this solution $10^{-7}$ were then carried out in a 96 well plate, and $20 \mu \mathrm{l}$ of each dilution factor from the 96 well plate was pipetted into a quadrant on a tryptone soya agar (TSA) plate of their respective dilution factor. These were then incubated at $37^{\circ} \mathrm{C}$ overnight, after which each quadrant was observed for growth and colonies counted. The number of colony-forming units (CFU) per $\mathrm{ml}$ from the original aliquot was calculated from this.

\section{Results}

\subsection{Optimising CCT with Catalytic Pre-Depostion Layer}

\subsection{1. $80 \mathrm{~h}$ Treated Coupons at Temperatures of 580, 620 and $660{ }^{\circ} \mathrm{C}$}

Coupons with and without a pre-deposition layer of $\mathrm{Pd} / \mathrm{Ag}$ were treated for $80 \mathrm{~h}$ at temperatures of 580,620 and $660{ }^{\circ} \mathrm{C}$. Formed surface oxide layer thickness and corresponding surface hardness of the samples are charted in Figure 1a,b. It was found that the Pd/Ag pre-deposition layer played a catalytic role on the ceramic conversion treatment as the surface layer thickness significantly increased up to 32 times compared with the bare surface ceramic conversation treatments. Observations of the three different temperature treated coupons determined that the $660^{\circ} \mathrm{C}$ treatment demonstrated a thick $100 \mu \mathrm{m}$ hardened surface layer, possessing an over 1000 Vickers hardness with a good interfacial adhesion, which stands out as an ideal treatment temperature for further treatment development.

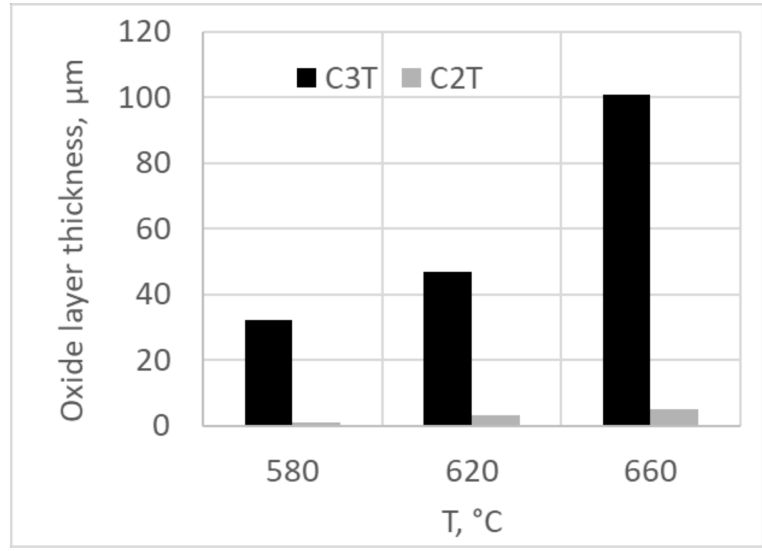

(a)

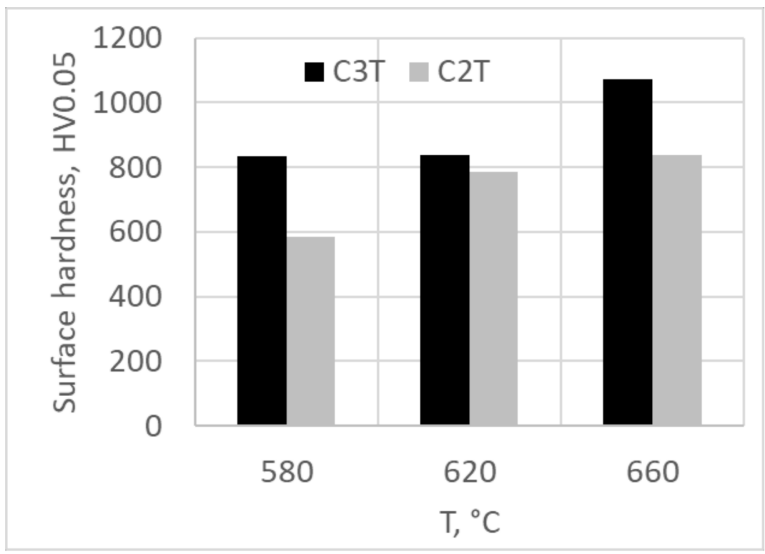

(b)

Figure 1. Oxide layer thickness (a) and surface hardness (b) of samples with and without a pre-deposition layer of $\mathrm{Pd} / \mathrm{Ag}$ vs. ceramic conversion treatment of $80 \mathrm{~h}$ at different temperatures.

\subsubsection{Ceramic Conversion Treatment of $660^{\circ} \mathrm{C}$ for a Series of Time Durations}

Figure 2 charts the oxide layer thickness of C2T and C3T samples and surface hardness of the C3TPdAg coupons treated at $660^{\circ} \mathrm{C}$ for different durations. It can be seen that the $\mathrm{Pd} / \mathrm{Ag}$ pre-deposition layer resulted in a much thicker oxide layer than the coupons without pre-deposition. A significant catalytic effect of $\mathrm{Pd} / \mathrm{Ag}$ on the formation of the oxide layer on Ti-6Al-4V was observed and a growth rate of about $2 \mu \mathrm{m} / \mathrm{h}$ was extrapolated from Figure 2a for C3T treated coupons when treated within $50 \mathrm{~h}$. This was 25 times faster than that of the C2T treatment coupons within the same time period. When the treatment time increases to over $60 \mathrm{~h}$, the oxide layer growth rate was reduced to $0.5 \mu \mathrm{m} / \mathrm{h}$, but this is 
still 6 times higher than the growth rate of C2T samples. Surface hardness evaluation of C3T treated coupons revealed a generally increasing trend with increasing treatment duration to a maximum of $1053 \mathrm{HV} 0.25$, except for the $5 \mathrm{~h}$ treated sample, which shows a relatively higher hardness value of 1128 HV0.25. It can be seen that a short treatment time of $5 \mathrm{~h}$ produced a $14.60 \mu \mathrm{m}$ hardened surface oxide layer, which is one of the purposes of this study. Further investigation was conducted under the treatment condition of $660{ }^{\circ} \mathrm{C} 5 \mathrm{~h}$ with $\mathrm{Ag}$ or Pd pre-deposited, to investigate the catalytic effect of the individual elements.

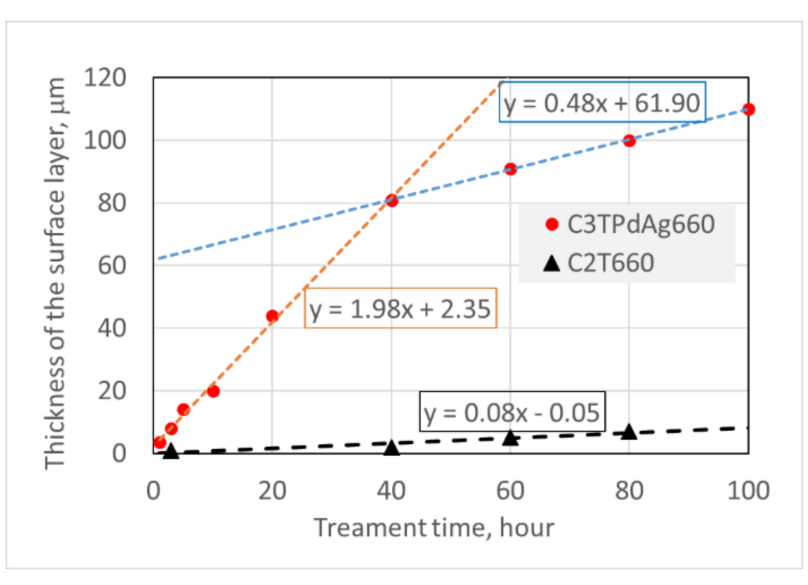

(a)

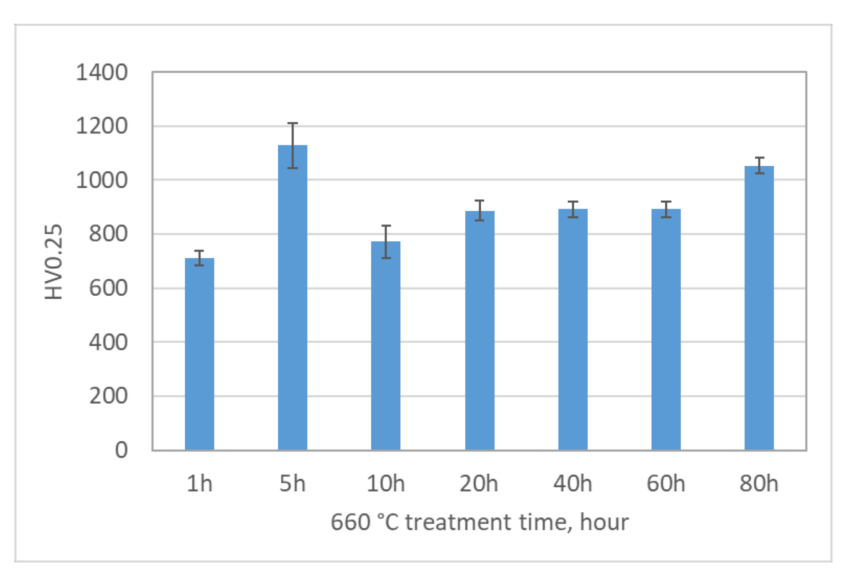

(b)

Figure 2. Surface layer (a) thickness of C3TPdAg660 and C2T660 samples and (b) hardness of C3TPdAg samples treated at $660^{\circ} \mathrm{C}$ for different time periods.

\subsection{3. $660{ }^{\circ} \mathrm{C} 5 \mathrm{~h}$ Treatment of Ag, Pd and Ag + Pd Pre-Deposited Coupons}

Coupons with pre-deposited coatings of $\mathrm{Ag}, \mathrm{Pd}$ and $\mathrm{Ag} / \mathrm{Pd}$ were ceramic conversion treated at $660^{\circ} \mathrm{C}$ for $5 \mathrm{~h}$ with the uncoated coupons for comparison. Figure 3a-d show the SEM images of these treated samples, where the left images are of surface morphology and right are of cross-section surface layer structures. It reveals that the $660^{\circ} \mathrm{C} 5 \mathrm{~h}$ treated C2T sample was covered by a smooth and fine roundish shaped oxide (Figure 3a left). The surface morphology of the C3T samples presented different features depending on pre-coating element. For Ag pre-coated samples, the oxides presented in bunches of acicular grains (Figure $3 \mathrm{~b}$ left). When Pd was pre-coated, the sample surface was covered by clusters of fine grains (200-300 nm) after the treatment (Figure 3c left). While for Ag and $\mathrm{Pd}$ co-deposited samples, oxides were shaped in micro-grains with a few thin needles (Figure 3d left). Corresponding cross-sectional microstructures of these four samples show a formed surface oxide layer in the thickness of 1.21, 11.40, 2.10 and $14.60 \mu \mathrm{m}$ for C2T, C3TAg, C3TPd and C3TAgPd samples, respectively. For Ag and Ag + Pd pre-coated coupons, white contrasted particles (corresponding to the surface granular grains) are present on the outermost surface (Figure $3 b, d$ ) and some are imbedded within the oxide layer, as denoted by arrows. Surface roughness of the samples are varying from 0.082, $0.278,0.090$ to $0.349 \mu \mathrm{m}$ for C2T, C3TAg, C3TPd and C3TPdAg samples, respectively.

Additionally, the surface hardness measured under $50 \mathrm{~g}$ show increased hardness of the samples with pre-coatings, especially for the co-deposited Pd/Ag samples.

Table 2 lists all observed data in terms of the surface layer thickness, hardness and roughness for these four samples. Summarising the observations, it is clear that the codeposition of Pd/Ag not only catalyses oxide layer formation, but also produces an even harder layer than single element pre-deposition. 


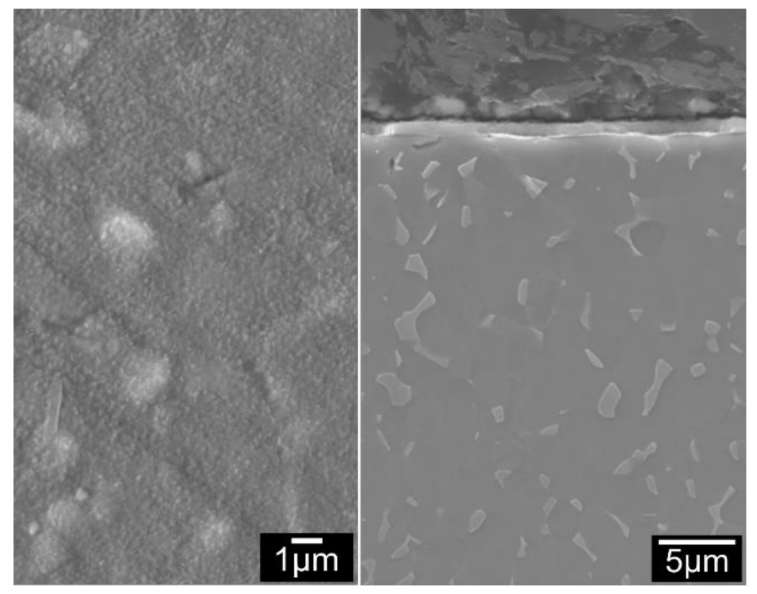

(a)

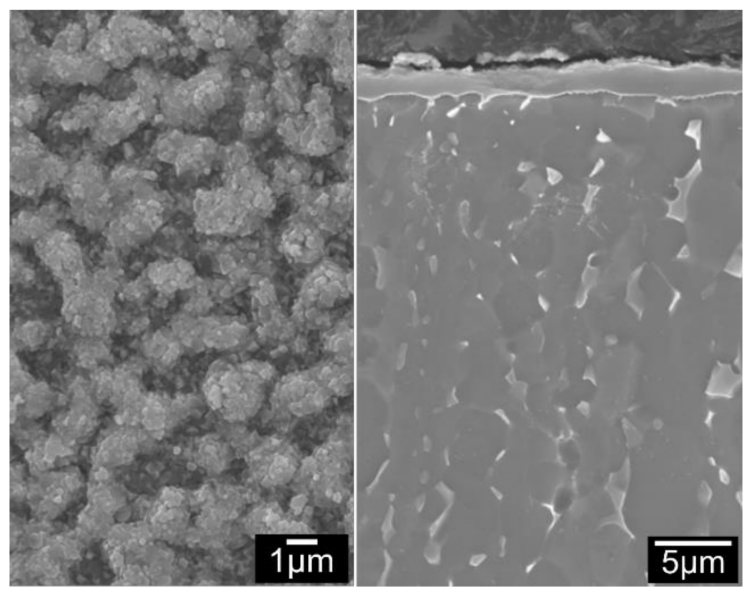

(c)

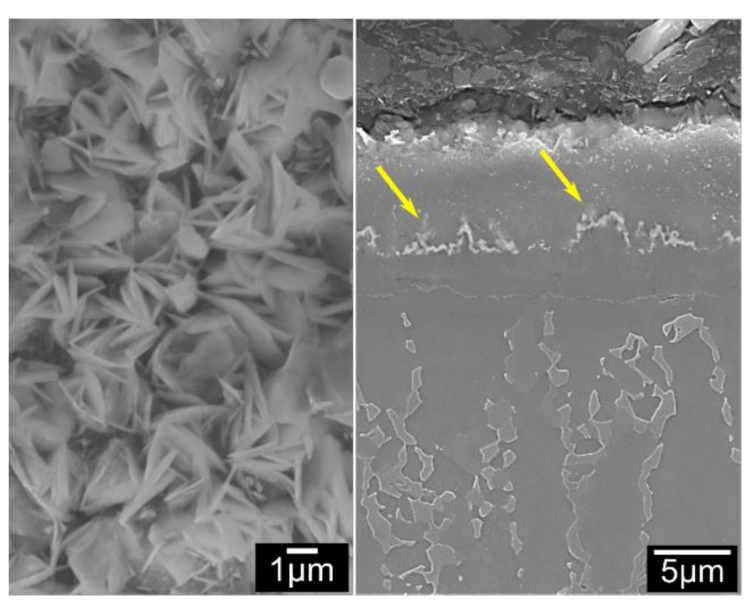

(b)

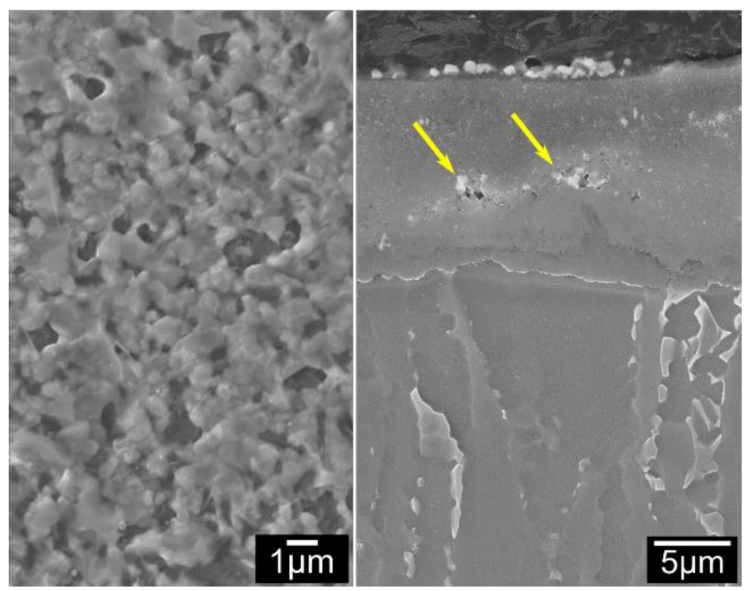

(d)

Figure 3. Surface morphology (left) and layer structure (right) of $660^{\circ} \mathrm{C}$, 5h treated Ti6Al4V samples: (a) no catalytic layer; (b) with Ag, (c) Pd and (d) PdAg catalytic pre-depositions.

Table 2. Surface layer thickness, hardness and roughness for $660{ }^{\circ} \mathrm{C}-5 \mathrm{~h}$ treated samples with and without pre-coating elements (for sample code details see Table 1).

\begin{tabular}{ccccc}
\hline $\mathbf{6 6 0 - 5 h}$ & Thickness, $\boldsymbol{\mu m}$ & HV0.05 & HV0.025 & Ra, $\boldsymbol{\mu m}$ \\
\hline C2T & 1.21 & $612+/-34$ & $931+/-20$ & $0.082+/-0.005$ \\
\hline C3TAg & 11.4 & $720+/-52$ & $1067+/-72$ & $0.278+/-0.037$ \\
\hline C3TPd & 2.10 & $686+/-96$ & $1099+/-68$ & $0.090+/-0.011$ \\
\hline C3TPdAg & 14.6 & $853+/-51$ & $1128+/-82$ & $0.349+/-0.025$ \\
\hline
\end{tabular}

\subsection{Microstructure Characterisation of Surface Oxide Layers}

\subsubsection{Surface Morphology Evolution of C3T Pd/Ag Coupons}

SEM observation on surfaces of all C3TPd/Ag coupons revealed that the surface morphology of the coupons present three typical features as shown in Figure 4a for treatment durations of $1-5 \mathrm{~h}$, surface oxides shaped as micro-grains with a few thin needles; Figure $4 \mathrm{~b}$ for treatment durations between 10 to $60 \mathrm{~h}$, the surface is composed of agglomerated micro-grains and fine, disordered needles and the blocks of the agglomerated grains were reduced with increasing treatment duration; and Figure $4 \mathrm{c}$ over $60 \mathrm{~h}$ treatment durations, the agglomerated micro-grains transformed to faceted grains and the needles were changed to rods. 


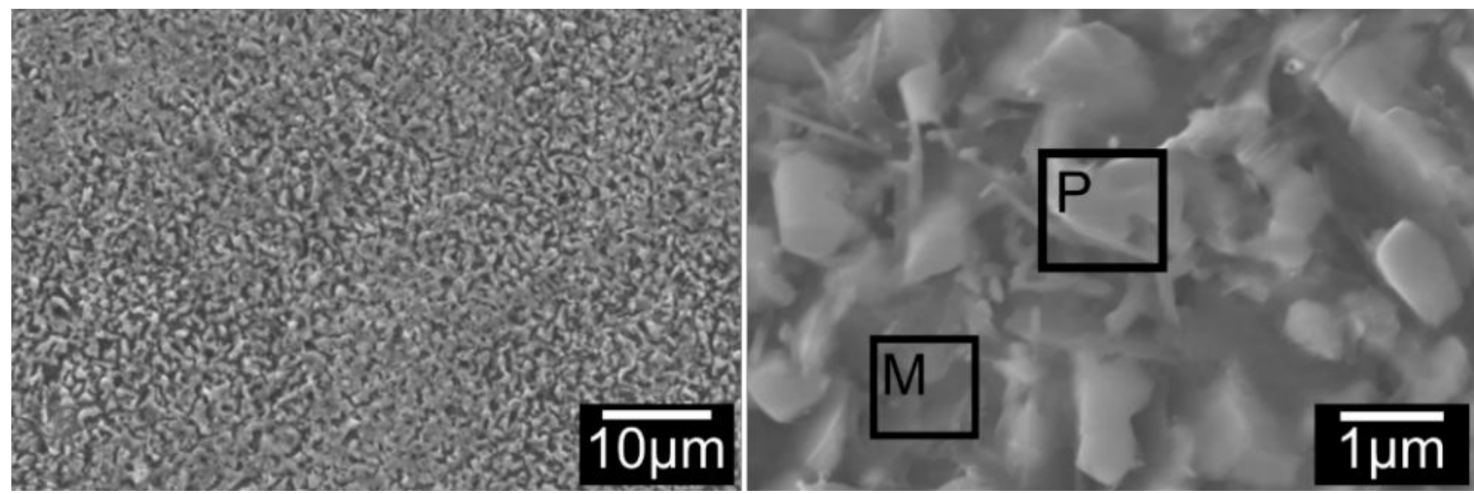

(a)

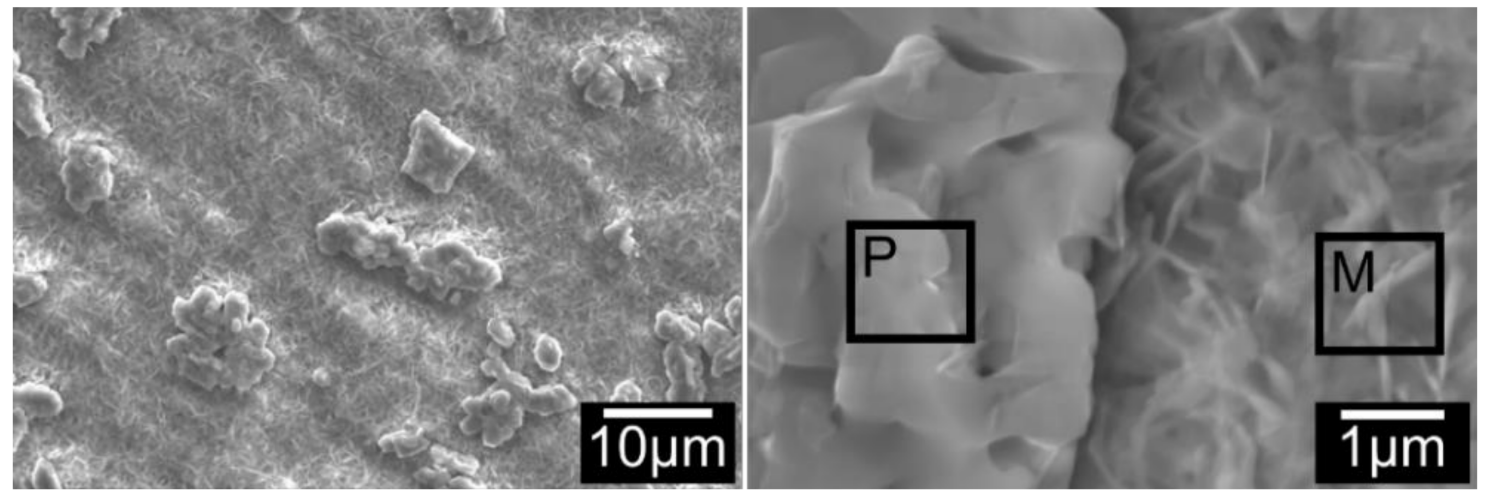

(b)

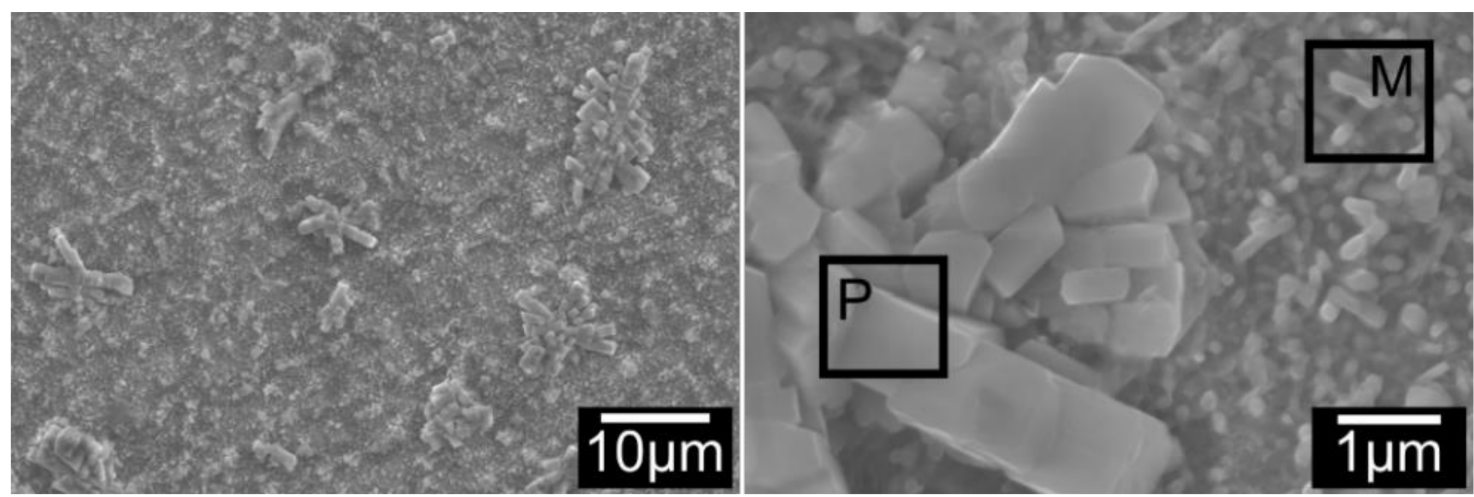

(c)

\begin{tabular}{|c|c|c|c|c|c|c|}
\hline \multirow{2}{*}{ Elements, wosition \& coupon } & \multicolumn{3}{|c|}{ On particles } & \multicolumn{3}{|c|}{ On Matrixes } \\
\hline & $660^{\circ} \mathrm{C}, 5 \mathrm{~h}$ & $660^{\circ} \mathrm{C}, 10 \mathrm{~h}$ & $660^{\circ} \mathrm{C}, 80 \mathrm{~h}$ & $660^{\circ} \mathrm{C}, 5 \mathrm{~h}$ & $660^{\circ} \mathrm{C}, 10 \mathrm{~h}$ & $660^{\circ} \mathrm{C}, 80 \mathrm{~h}$ \\
\hline $\mathrm{Ag}$ & 30.49 & 1.83 & 0.25 & 6.98 & 7.19 & 0.24 \\
\hline $\mathrm{Pd}$ & 54.12 & 72.87 & 73.40 & 0.38 & 0.16 & 0.32 \\
\hline $\mathrm{Ti}$ & 3.00 & 2.20 & 4.51 & 33.76 & 31.94 & 50.88 \\
\hline Al & 3.72 & 3.94 & 2.06 & 18.72 & 19.10 & 11.04 \\
\hline V & 0.40 & 1.09 & 0.45 & 3.79 & 5.25 & 1.90 \\
\hline 0 & 8.27 & 18.08 & 19.34 & 36.37 & 36.26 & 35.64 \\
\hline
\end{tabular}

(d)

Figure 4. Surface morphology change of C3TAgPd coupons, treated at $660{ }^{\circ} \mathrm{C}$ for (a) $5 \mathrm{~h}$; (b) $10 \mathrm{~h}$ and (c) $80 \mathrm{~h}$. ' $\mathrm{P}^{\prime}$ and 'M' denote particle and matrix, respectively; (d) elemental analysis on the spots of agglomerated particles and matrix grains for 5, 10 and $80 \mathrm{~h}$ treated coupons (see denoted $\mathrm{P}$ and $\mathrm{M}$ in $\mathrm{a}, \mathrm{b}, \mathrm{c}$ ). 
EDX mapping on the top surfaces of C3TPdAg coupons revealed elemental distribution along the surface features: all agglomerated/faceted micro-grains are composed of $\mathrm{Ag}, \mathrm{Pd}$ and $\mathrm{O}$, and acicular (or matrix) grains are detected as $\mathrm{V}, \mathrm{Ag}, \mathrm{Al}, \mathrm{O}$ and Ti. The quantified EDX spot analysis on the agglomerated grains and the acicular/matrix grains for 5,10 , and $80 \mathrm{~h}$ treated coupons are listed in Figure $4 \mathrm{~d}$. By comparing the quantity change trends on the particles and matrixes, it is very interesting to see that it was the Pd which agglomerated during the treatments, evidenced by it presenting dominantly in the particles. While for $\mathrm{Ag}$, it was initially present within the particles dominantly (30.49 wt $\%$ for $5 \mathrm{~h}$ ), and then reduced to 1.83 and $0.25 \mathrm{wt} \%$ after 10 - and $80 \mathrm{~h}$ treatments, respectively. Its distribution in the matrix ground was kept constant $(\approx 7 \mathrm{wt} \%)$ within $10 \mathrm{~h}$ treatment and then reduced to $0.25 \mathrm{wt} \%$ for the $80 \mathrm{~h}$ treated coupon, indicating its diffusivity into the formed oxide layer. High Al content was observed on the matrix for all treated coupons, alluding to alumina forming at the surfaces.

\subsubsection{Phase Identification by XRD Patterns}

XRD patterns of the typical C2T and C3TPdAg treated samples are shown in Figure 5 with untreated for comparison. As indexed, the untreated Ti-6Al-4V is composed of predominantly alpha-Ti phase and a few weak peaks of beta-Ti. After C2T treatment, rutile $\mathrm{TiO}_{2}$ phase was identified with weak peaks of alpha-Ti, which was contributed from the substrate as the formed oxide layer is only about $3 \mu \mathrm{m}$. For the C3T treated sample, in addition to the high intensity peaks of the rutile $\mathrm{TiO}_{2}$ phase, a new set of peaks was identified as a PdO phase (JCPDS 00-043-1024) and peaks of pure Ag phase were also detected. Some more peaks with low intensity could not be assuredly indexed to other oxides, such as $\mathrm{Al}_{2} \mathrm{O}_{3}, \mathrm{AgO}_{2}$ and $\mathrm{V}_{2} \mathrm{O}_{5}$ etc. phases.

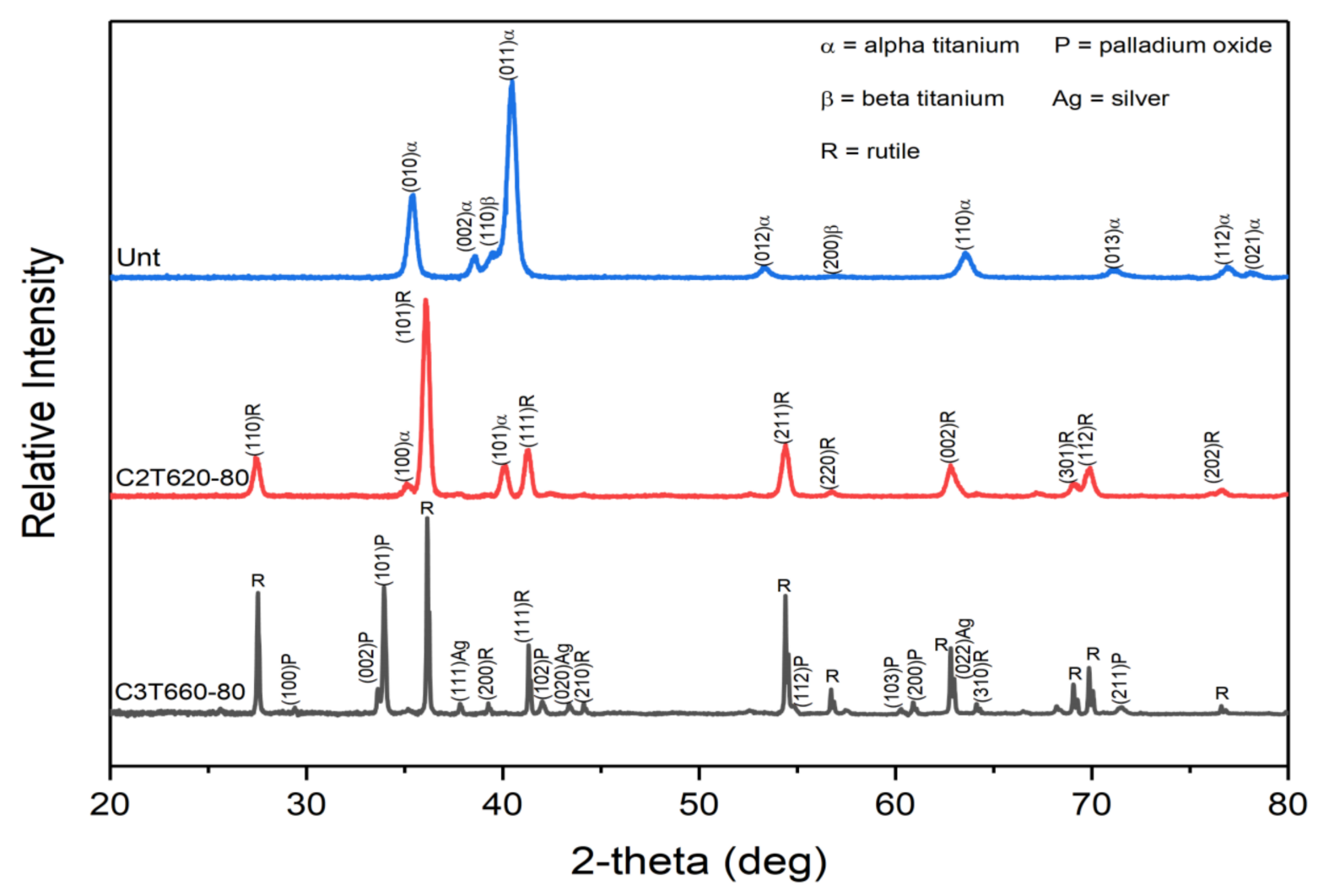

Figure 5. XRD patterns of as-received (Unt), C2T620-80 and C3T660-80PdAg samples. 


\subsubsection{FIB/SEM and TEM Characterisation of the Surface Layer Structures}

Further TEM characterisation was carried out on a C3T660-10PdAg coupon. A crosssection TEM sample was prepared by FIB, and the sampling position is across the agglomerated $\mathrm{Pd}(\mathrm{Ag})$ particle and the acicular matrix, as shown in Figure 6a. A STEM HAADF image and corresponding EDX elemental mappings of the TEM sample are shown in Figure $6 \mathrm{~b}-\mathbf{i}$, which reveal cross-sectional surface oxide layer structures as shown by chemical composition distributions. An added dashed line on each element mapped image indicates the boundary between the topmost 'catalytic' layer and the dominant $\mathrm{TiO}_{2}$ layer beneath. Combining the top morphology of the FIB sampling position (Figure 6a) with the cross-sectional view of the HDDF STEM image Figure 6b) and the EDX elemental mappings, it can be determined that: above the dashed line, the white contrasted grains at either side of the image (Figure $6 \mathrm{~b}$ ) are the agglomerated granular grains, and the grey middle area are acicular grains. EDX mappings show high intensities of $\mathrm{Ag}, \mathrm{Pd}$ and $\mathrm{O}$ elements within the granular grains, while the needle shaped grains are indicating a composition of $\mathrm{V}, \mathrm{Ag}, \mathrm{O}, \mathrm{Al}$ and $\mathrm{Ti}$ (trace). Interestingly, $\mathrm{Al}$ combined with $\mathrm{O}$ presented along the grain boundaries of the granular and acicular grains of the topmost layer. Beneath the topmost layer, compositional elements of alloy $\mathrm{Ti}-6 \mathrm{Al}-4 \mathrm{~V}, \mathrm{Ti}, \mathrm{Al}, \mathrm{V}$, are all presented with $\mathrm{O}, \mathrm{Ag}$ and Pd (low contrast).
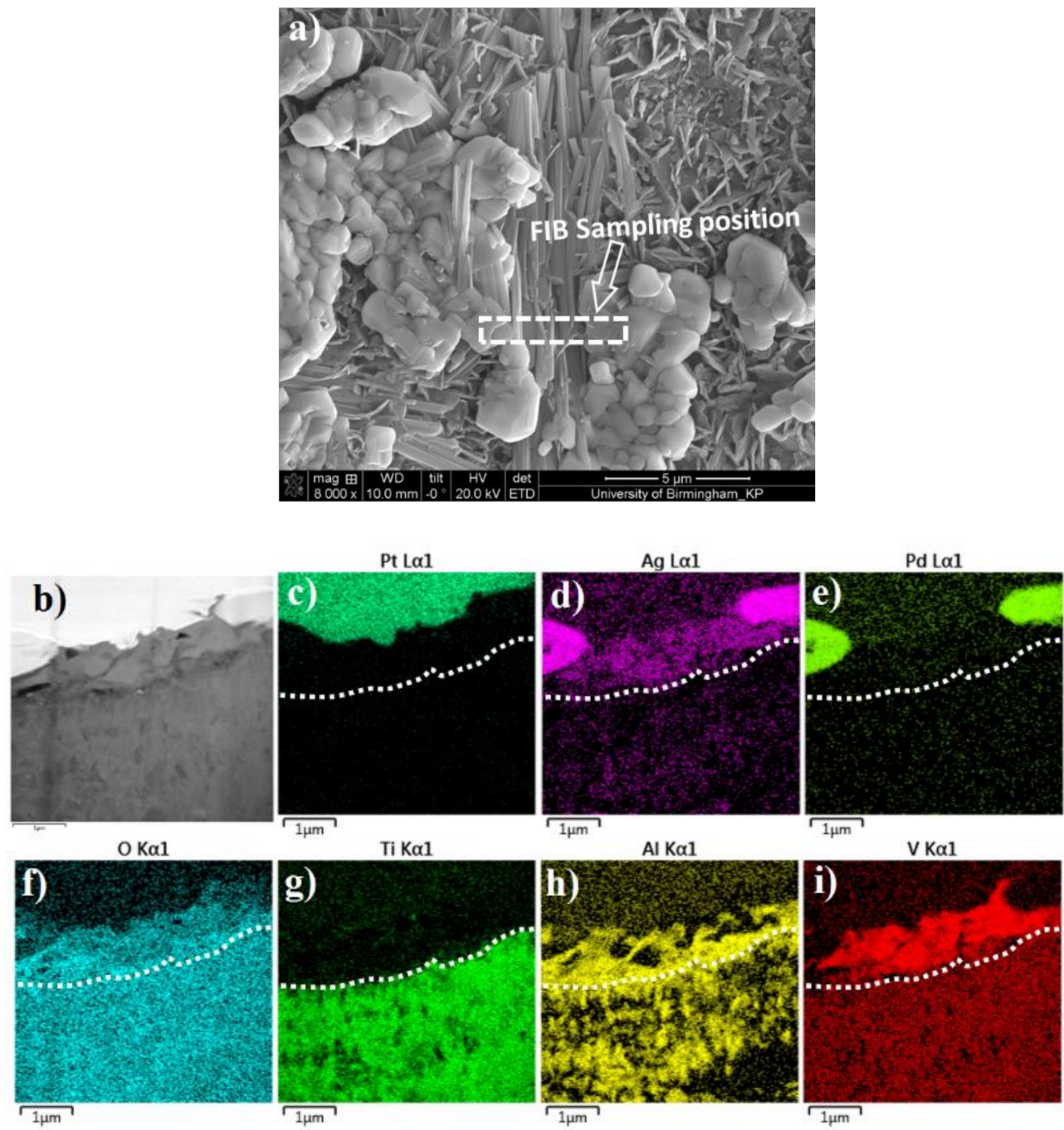

Figure 6. FIB sampling location (a); and HAADF image (b), of a TEM sample of C3T660-20AgPd coupon; (c-i) STEM-EDX element mapping for elements $\mathrm{Pt}, \mathrm{Ag}, \mathrm{Pd}, \mathrm{O}, \mathrm{Ti}, \mathrm{Al}, \mathrm{V}$, respectively. Pt layer shown in (c) was deposited during the $\mathrm{FIB}$ sample preparation. A dash lines were added to indicate the boundary between the 'catalytic' topmost substances and the beneath $\mathrm{TiO}_{2}$ layer. 
Further TEM observation and SAD pattern analysis specified the phase composition of the oxide layer structures. As can be seen from Figure 7a, the surface oxide layer consists of a topmost layer with granular and acicular grains and a dominant columnar structured sublayer. It was observed that just beneath the topmost catalytic layer an approximately $500 \mathrm{~nm}$ thickness layer is present, with a nano-crystalline structure (50-100 nm diameter). Beneath this nano-grained layer, the columnar structure is evident and developed to the front of the substrate with column widths of approximately 100-200 nm and lengths of approximately 400-600 $\mathrm{nm}$.
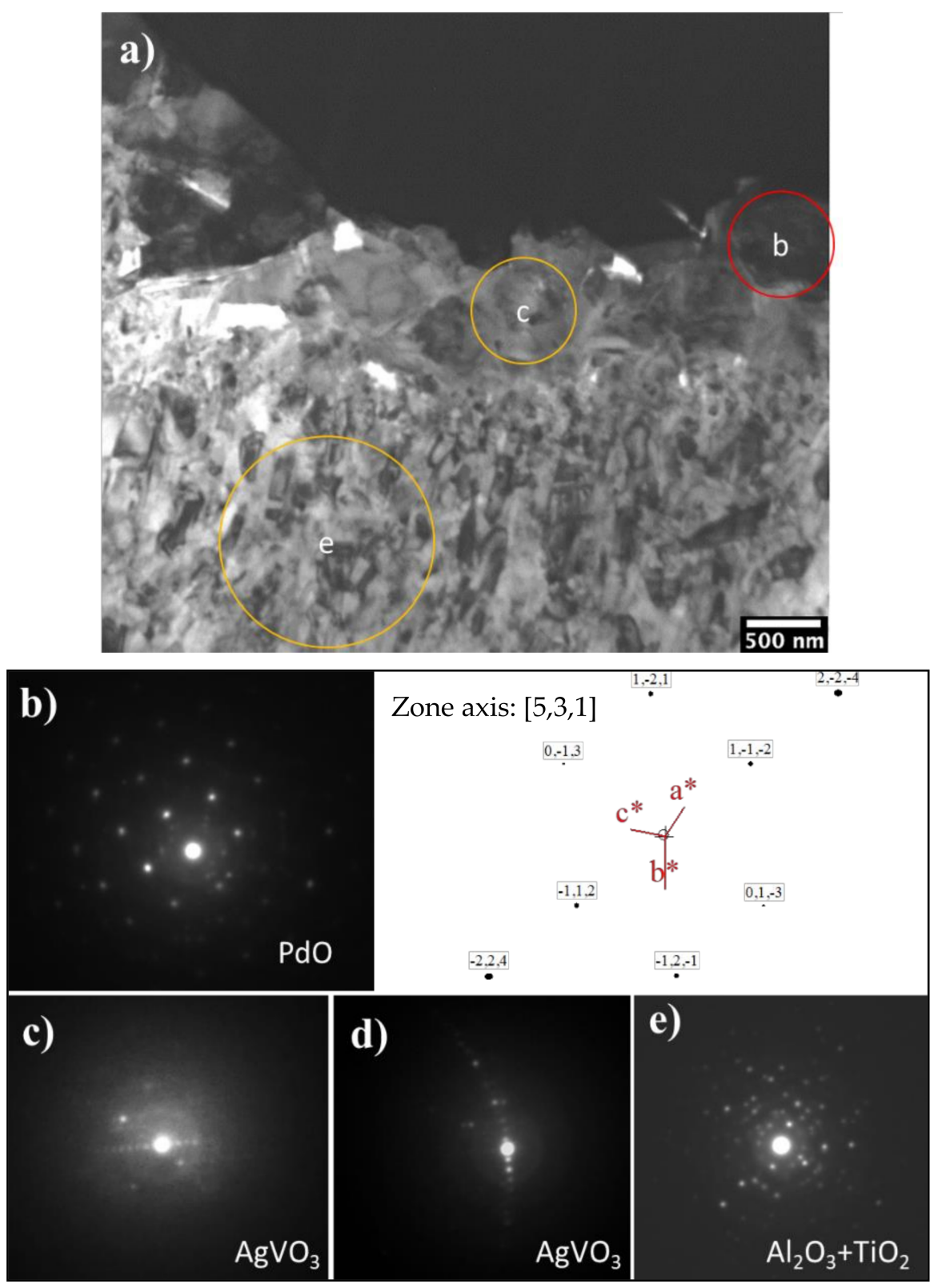

Figure 7. (a) BF-TEM of C3T660-10PdAg and corresponding SAD patterns. Region b corresponds to (b), region c corresponds to (c) and (d), and region e corresponds to (e). Areas of b, c, e are denoted in (a-e) indicate phases of $\mathrm{PdO}, \mathrm{AgVO}_{3}, \mathrm{TiO}_{2}$ and $\mathrm{Al}_{2} \mathrm{O}_{3}$ as labelled.

SAD patterns taken from the granular grains were identified as a PdO phase, evidenced by a $B=[531]$ pattern shown in Figure 7a,b, which is consistent with the XRD peaks indexing of $\mathrm{PdO}$ in Figure 5. No Ag oxides could be identified from the diffraction patterns taken from the granular grains. As the EDX detected co-existing of $\mathrm{Ag}$, $2 \mathrm{wt} \%$, with $\mathrm{Pd}$ in the granular grains (see Figure $4 \mathrm{~d}$ ), a PdO-like oxide with some of the Pd being substituted 
by $\mathrm{Ag}$, or a $\mathrm{Pd}(\mathrm{Ag}) \mathrm{O}$ phase, was considered for the granular grains. Another possibility of an $\mathrm{Ag}$ capping layer on top of the Pd particles cannot be ruled out. Prior studies show that PdAg surfaces can be highly dynamic at modest temperatures and heating to only $400 \mathrm{~K}$ in UHV promoted the formation of an Ag capping layer on top of the Pd islands, thereby lowering the surface free energy as the surface free energy of Pd is 1.6 times higher than that of $\mathrm{Ag}[19,20]$.

Indexing the $\mathrm{SAD}$ patterns of the acicular grains identified an $\mathrm{AgVO}_{3}$ (JCPDS 0029-1152) phase (Figure $7 \mathrm{a}, \mathrm{c}, \mathrm{d}$ ). Faint diffraction rings were always superimposed in the $\mathrm{Pd}(\mathrm{Ag}) \mathrm{O}$ and $\mathrm{AgVO}_{3}$ patterns, which could be contributed to an amorphous or poorly crystalline structure of aluminium oxide based on the fact that $\mathrm{Al}$ was presented among the grain boundaries of these grains, as seen from the EDX mapping in Figure $6 \mathrm{~h}$, but it is difficult to identify the $\mathrm{Al}_{2} \mathrm{O}_{3}$ phase from the $\mathrm{SAD}$ patterns taken in these areas.

SAD patterns taken from the columnar-grained layer show some discrete rings, which denote the polycrystalline nature of the layer and one example is presented in Figure 7e). Indexing of the discrete rings identified a dominant rutile $\mathrm{TiO}_{2}$ phase with a few rings corresponding to $\mathrm{Al}_{2} \mathrm{O}_{3}$. Although EDX analysis shows $\mathrm{Ag}$, $\mathrm{Pd}$ and $\mathrm{V}$ elements presenting (Figure $6 \mathrm{~d}, \mathrm{e}, \mathrm{i}$ ) within this layer, no other oxides could be identified from the SAD patterns taken from this layer, suggesting that these elements either present as substitute elements to $\mathrm{Ti}$ in the $\mathrm{TiO}_{2}$ phase or as pure elements. It was observed that the interface between the columnar oxide layer and the substrate are dense and without voids. The SAD patterns taken from the substrate adjacent to the oxide layer revealed an expanded HCP structure of $\alpha-\operatorname{Ti}(\mathrm{O})$, or oxygen diffusion zone.

\subsection{Mechanical and Tribological Properties of the Treated Coupons and Pins}

From Section 3.1., it is found that co-depositing Pd/Ag on Ti-6Al-4V (Ti64) prior to ceramic conversion treatment can effectively catalyse surface oxide layer growth and the formed surface layer possesses a high hardness of 700-1100 HV 0.025 (Figure 2b). Table 2 compares surface micro-hardness of the typical C3T coupons with $\mathrm{C} 2 \mathrm{~T}$ coupons. It can be seen that the $\mathrm{C} 2 \mathrm{~T}$ and $\mathrm{C} 3 \mathrm{~T}$ treatments produced a hardened surface layer with the hardness value of 931 and $1128 \mathrm{HV} 0.025$, respectively. This is approximately 2.5 and 3.1 times the hardness values of the untreated Ti64 coupons ( 360 HV 0.025).

Reciprocating tests were carried out under two loads on selected C3T samples of $660^{\circ} \mathrm{C}, 5,20$ and $80 \mathrm{~h}$ treated, compared with C2T treated and untreated (Unt) samples. When the wear tests were carried out under the normal load below $15 \mathrm{~N}$, no measurable wear scars can be detected for both the C2T and C3T treated samples. The selected C3T coupons performed similar but excellent wear resistance under the two loads selected and the typical wear factor of the C3T coupons is compared with the $\mathrm{C} 2 \mathrm{~T}$ and untreated ones in Figure 8. It can be seen that under the normal load of $15 \mathrm{~N}$, there was no measurable wear for the C3T samples but the wear factor of C2T is $\approx 56 \times 10^{-15} \mathrm{~m}^{3} / \mathrm{N}$.m. It was only when the normal load increased to $50 \mathrm{~N}$, a marginable wear scar could be seen and thus the wear factor can be measured/calculated for the C3T samples, which was 1/350 of the wear factor of C2T and Unt coupons. Compared with Unt Ti64, C2T demonstrated a 30 times reduction in wear factor when tested under the load of $15 \mathrm{~N}$. However, when further increasing the test load to $50 \mathrm{~N}$, the improvement was marginal for C2T vs. Unt coupons. This is because the surface layer of $\mathrm{C} 2 \mathrm{~T}$ is very thin, and when it is tested with a heavy load, excessive plastic deformation in the substrate occurred, and the wear debris from the hardened surface acted as the third body. This resulted in the reduced tribological properties shown [21]. It should also be noted from Figure 8 that the wear factor is larger under the lower load of $15 \mathrm{~N}$ than under the higher load of $50 \mathrm{~N}$ for the Unt samples. This phenomenon is believed to be due to the fact that although there was a 3.3 times increase in load ( 15 to $50 \mathrm{~N})$, there is not a 3.3 times increase in contact pressure. This is due to the untreated Ti64 undergoing more deformation at the higher load, thus increasing the contact area between the substrate and counterpart, therefore reducing the contact pressure. This is not taken into consideration in the wear factor calculation. Additionally, the higher load 
may have caused a sufficient temperature increase between the substrate and counterpart during wear, which induced the generation of a tribofilm consisting of oxidised Ti64 wear particles, thus increasing wear resistance of the Ti64 [22].

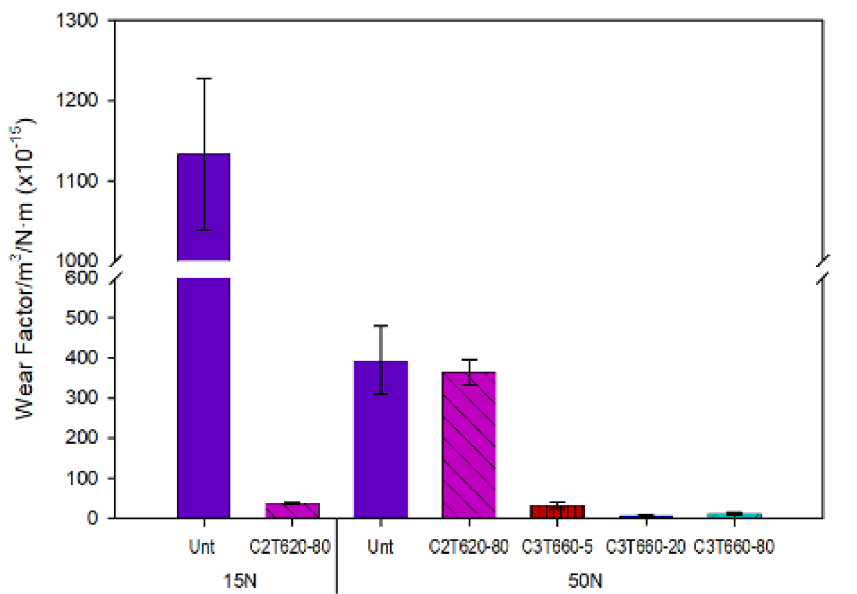

(a)

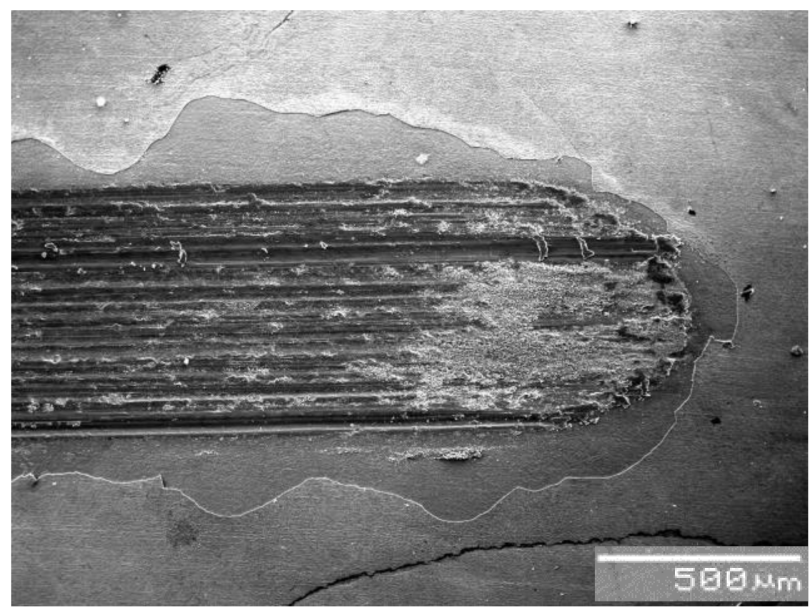

(c)

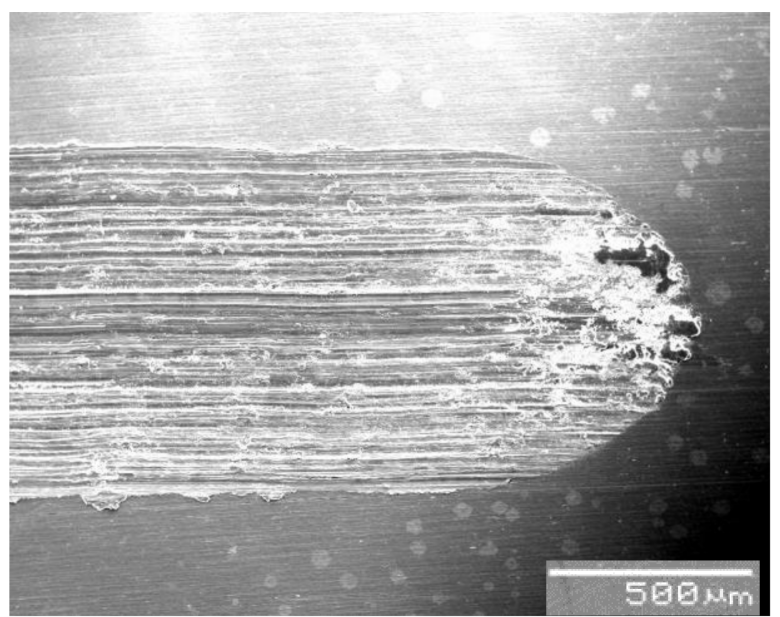

(b)

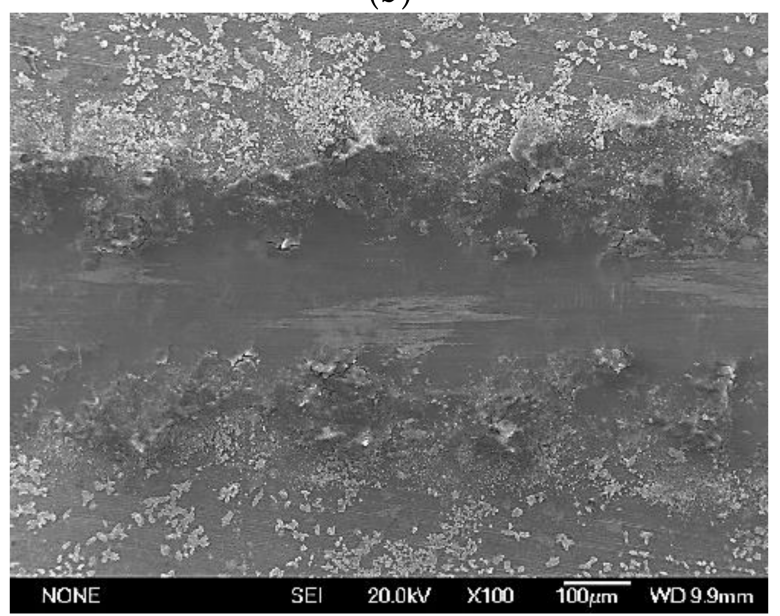

(d)

Figure 8. (a) Wear factors of Untreated, C2T and typical C3T coupons; SEM images of the wear tracks after $50 \mathrm{~N}$ wear tests for the coupons of (b) untreated; (c) C2T620-80 and (d) C3T660-5PdAg.

SEM observation of the wear tracks of the C3T660-5PdAg sample tested under $50 \mathrm{~N}$ revealed a polished smooth surface rather than a wear track as evidenced in Figure $8 \mathrm{~d}$. While for Unt and C2T samples, severe wear tracks were formed after the tests under $50 \mathrm{~N}$. The Unt samples displayed severe adhesive wear characterised by the plastic deformation and adhesion junctions between the counterparts. In addition, the asperities of the counterpart, a WC ball, exerted a significant ploughing effect on the Unt sample, resulting in dense deep and wide grooves shown in Figure 8b, features indicating abrasive wear [23,24]. For C2T samples, the wear tracks featured surface oxide layer chip-off and abrasive wear groves, which was caused by the heavy load applied. During the wear tests, the counterpart wore through the oxide layer and the hard oxide debris acted as a third body, abrasively wearing into the underlying bulk material (Figure 8c).

The recorded axial forces, $\mathrm{Fz}$, needed to achieve the insertion distance of $25 \mathrm{~mm}$ through the bone plate against the insertion time are shown in Figure 9a for Unt and C3T660-5PdAg pins. It can be seen that for the Unt pins, the applied axial force increased linearly before it reached the maximum force value, then dropped to a nearly constant 
force, with some fluctuation as the pin went through the bone simulation block. Finally, it rapidly reduced before it flattened at a low value after the pin fully went through the bone plates. Compared with the Unt pins, a significant reduction in the insertion force was observed for C3T treated pins. As can be seen from Figure $9 \mathrm{~b}$ that the mean/maximum insertion forces are $20 / 33 \mathrm{~N}$ for the treated, and $78 / 86 \mathrm{~N}$ for the untreated, a nearly four times reduction in mean insertional force of the $\mathrm{C} 3 \mathrm{~T}$ pins vs. the untreated pins. Post insertion test observation on the pin's tip at the cutting edge revealed severe damage for the Unt pins compared with the C3T treated pins, as evidenced in Figure 10. Compared with the new pin in Figure 10a, the cutting edge of the Unt and C3T treated pins have worn off approximately $85 \%$ and $9 \%$ of the tip volume, respectively, indicating a great performance of the C3T treated pins over the Unt ones, which could be attributed to the larger difference in hardness between the C3T treated $(1100 \mathrm{HV})$ and the untreated $(370 \mathrm{HV})$ surfaces.

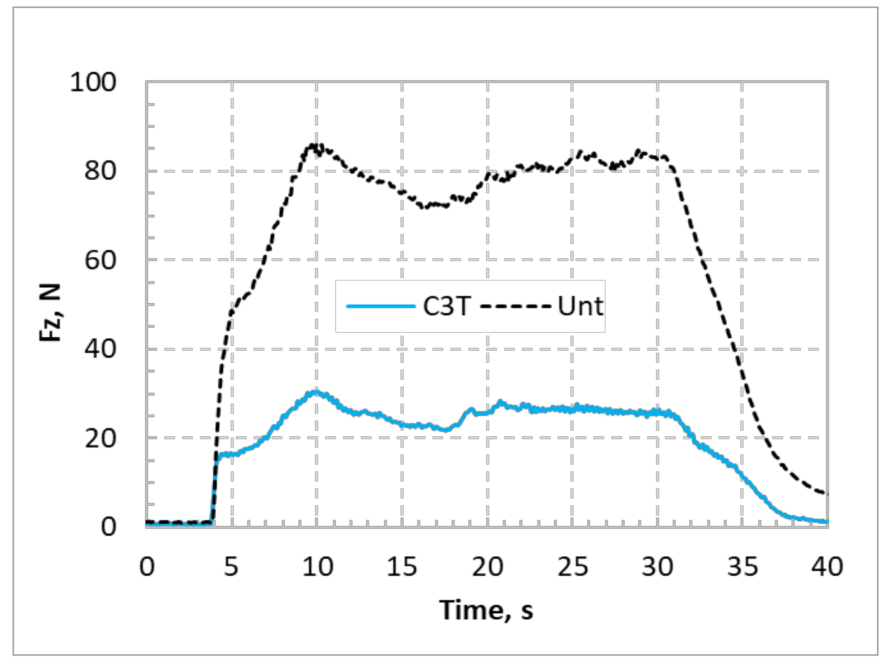

(a)

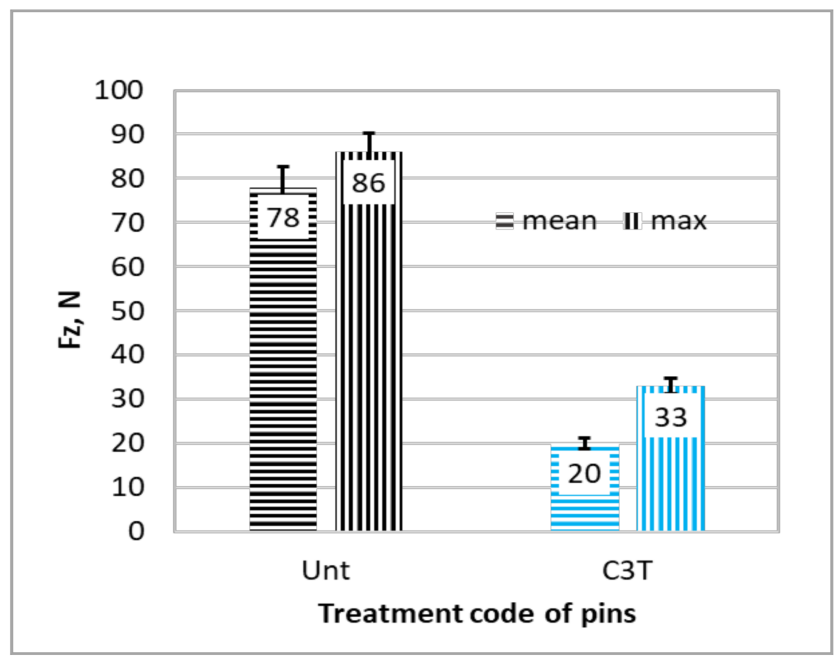

(b)

Figure 9. Comparisons of (a) recorded insertion forces against drilling time and (b) average and maximum insertion forces

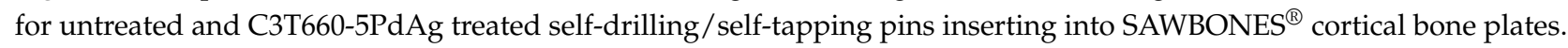

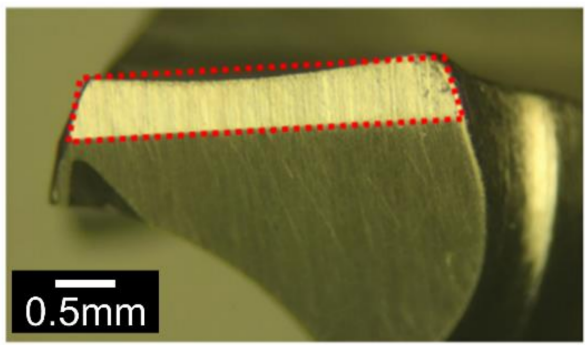

(a)

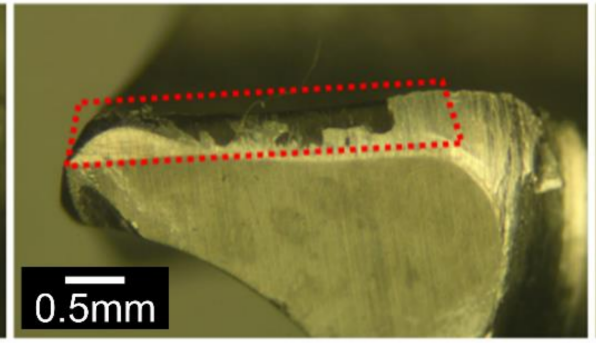

(b)

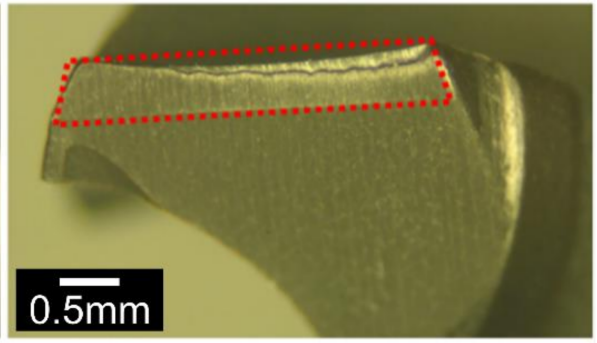

(c)

Figure 10. Optical images of cutting-edge areas of the pins: (a) as received new pin, (b) untreated, and (c) C3T660-5PdAg treated pins after insertion test with SAWBONES®cortical bone plates.

\subsection{Anti-bacterial Efficacy}

The antibacterial performance of Unt and treated Ti64 coupons is shown in Figure 11. Post $6 \mathrm{~h}$ incubation, the average number of viable colony-forming units (CFU) per ml of $S$. aureus inoculant reduced significantly $(\mathrm{P}<0.05)$ for both $\mathrm{C} 2 \mathrm{~T}$ and $\mathrm{C} 3 \mathrm{~T}$ coupons compared with Unt $\left(40 \times 10^{4}\right)$ coupons. C3T demonstrated a further significant $(\mathrm{P}<0.05)$ reduction vs. C2T, of $3 \times 10^{4}$ vs. $20 \times 10^{4}$, respectively. This clearly indicates that the ceramic conversion treatment can effectively improve the antibacterial efficacy of Ti64 alloy with approximately a 50\% reduction in the number of CFUs. Furthermore, the catalytic 
elements introduce an even greater significant increase in antibacterial performance, with a reduction in CFUs of 93\% compared with the Unt coupons.

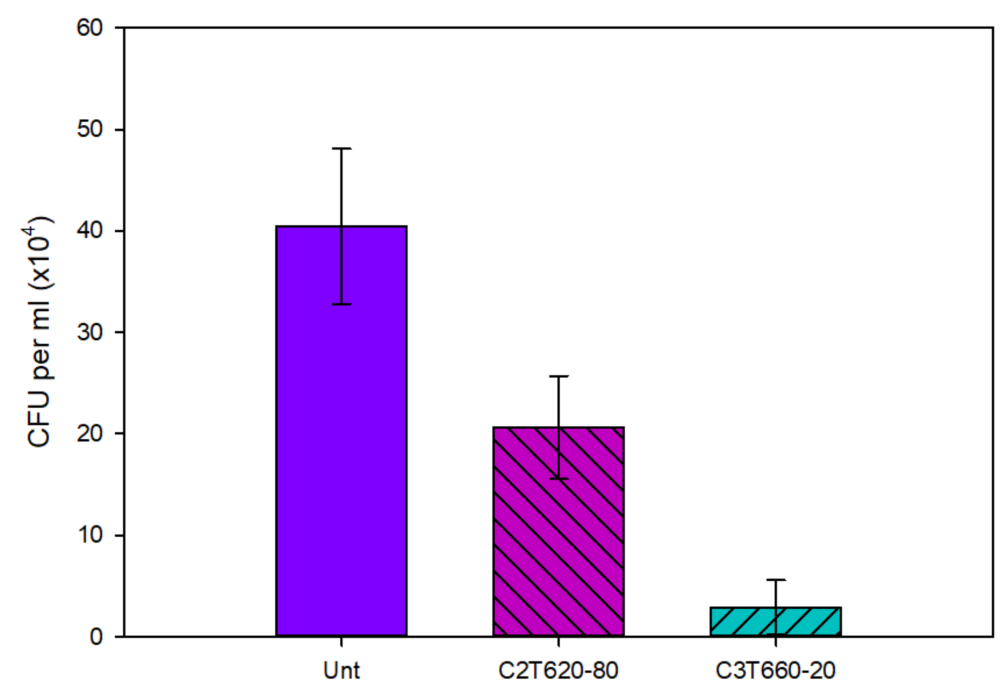

Figure 11. The antibacterial performance of untreated and treated Ti64. Where a smaller number of colony-forming units (CFU) is desirable. Note scale is multiplication.

\section{Discussion}

\subsection{Catalytic Effect on the Growth of the Oxide Layer}

It is clear from Figure $2 \mathrm{a}$ that coupons with a pre-deposition of a Pd/Ag layer significantly increased surface oxide layer growth rate by 25 times that of the C2T treatment coupons within the $50 \mathrm{~h}$ treatment durations. When the treatment duration increases to over $60 \mathrm{~h}$, the oxide layer growth rate of C3T coupons reduced to $0.5 \mu \mathrm{m} / \mathrm{h}$, but this is still 6 times higher than the growth rate of the C2T samples. SEM and TEM observation revealed the oxide layer surface morphology evolution and layer structure details. The catalytic effect of $\mathrm{Pd} / \mathrm{Ag}$ on the fast growth of the oxide layer can be drawn from the following aspects:

\subsubsection{Surface Morphology Evolution of C3T Pd/Ag Coupons}

For the Ti64 alloy, at low temperatures (or the initial oxidation period) in an oxidizing atmosphere, oxide scale formation follows these steps [1]: oxygen adsorption at the surface, oxide nucleation, lateral growth of the nuclei and formation of a compact oxide scale, which will then separate surface from the gaseous environment, thus retarding the oxidation processing. For pre-deposited Pd/Ag Ti64 samples, the surface deposition layer is very thin, which will not prevent titanium adsorption of oxygen. Instead, these nano-particles were blocking the lateral growth of the $\mathrm{TiO}_{2}$. This made the $\mathrm{TiO}_{2}$ grains form in the nanoscale, and in turn, those grain boundaries provided multiple tunnels for fast inward oxygen diffusion. Similar observations were reported by Prodromides et al. [25] on TiZrV getter films, where the presence of grain boundaries in the nanocrystalline structure promoted in depth diffusion of oxygen. This effect was continued until Pd particles were agglomerated to large particles and $\mathrm{Ag}$ was exhausted from the surface due to dispersion within the formed $\mathrm{TiO}_{2}$, as evidenced by the fact that the oxidation rate was reduced only after $60 \mathrm{~h}$.

\subsubsection{Nano-Crystallisation of Columnar $\mathrm{TiO}_{2}$ Grains by Finely Distributed Ag Particles}

STEM/EDX chemical composition mapping of the C3T660-20 PdAg sample (Figure 7) demonstrates movement of the pre-coated $\mathrm{Pd} / \mathrm{Ag}$ catalytic elements for treatment durations longer than $10 \mathrm{~h}$ at $660^{\circ} \mathrm{C}$. It revealed that $\mathrm{Pd}$ agglomerated at the surface and formed $\mathrm{PdO}$, while $\mathrm{Ag}$ particles were finely dispersed in the $\mathrm{TiO}_{2}$ layer, and the quantitative analysis of the Ag content in both particles and the matrix $\left(\mathrm{TiO}_{2}\right)$ further confirmed this observation (Figure 4d). Based on the Ellingham-diagram [26], $\mathrm{Ag}_{2} \mathrm{O}$ can be formed at low 
temperatures when oxidised in air. However, it is unstable above $462 \mathrm{~K}$ and the formed $\mathrm{Ag}_{2} \mathrm{O}$ will reduce to stable Ag metal. Due to Ti's strong affinity to $\mathrm{O}$, when Ti diffuses outwards to meet oxygen and form $\mathrm{TiO}_{2}$, the stable $\mathrm{Ag}$ particles act as doping elements pinning $\mathrm{TiO}_{2}$ grains, thus preventing them growing to a large size. This resulted in the formation of nano-crystalline columnar $\mathrm{TiO}_{2}$. This formed near vertical (to the sample surface) columnar grain boundaries between the nano-crystalline grains, thus acting as oxygen diffusion channels. The dispersion of Ag particles in the $\mathrm{TiO}_{2}$ matrix are in good agreement with Adochite et al. [27] who reported on a silver doped $\mathrm{TiO}_{2}$ system obtained by magnetron sputtering after annealing between $400-600{ }^{\circ} \mathrm{C}$, and such a phenomenon might have been induced by Ag diffusion along the $\mathrm{TiO}_{2}$ grain boundaries, as suggested by Armelao et al. [28].

On the other hand, the nano-crystaline columnar $\mathrm{TiO}_{2}$ grains prevented the formation of a lateral $\mathrm{Al}_{2} \mathrm{O}_{3}$ layer. According to Du et al. and Cimenoglu et al. [29,30] multi-layered oxides will form on the surface of Ti-6Al-V alloy with long duration oxidation, which is due to alternating growth of $\mathrm{Al}_{2} \mathrm{O}_{3}$ and $\mathrm{TiO}_{2}$ layers by outward diffusion of aluminium and inward diffusion of oxygen. At the early stages of oxidation, $\mathrm{Al}_{2} \mathrm{O}_{3}$ nucleates on the surface together with $\mathrm{TiO}_{2}$. At extended oxidation times, $\mathrm{Al}_{2} \mathrm{O}_{3}$ grows laterally and covers $\mathrm{TiO}_{2}$. In this case, the outer most section of the oxide layer (gas/oxide interface) is $\mathrm{Al}_{2} \mathrm{O}_{3}$, while the inner section of the oxide layer (oxide/substrate interface) is $\mathrm{TiO}_{2}$. Once the critical thickness is exceeded, cracks develop at the interface, where the conditions might be similar to the bulk atmosphere of the early stage of oxidation. Aluminium from the substrate would again diffuse outward and form the second $\mathrm{Al}_{2} \mathrm{O}_{3}$ layer on the second $\mathrm{TiO}_{2}$ layer in the crack. However, this lateral structure, and thus the cracks, were not observed within the C3T coupons even after $80 \mathrm{~h}$ treatment. The finely distributed Ag within columnar nano-crystalline $\mathrm{TiO}_{2}$ grains firstly prevented the lateral $\mathrm{TiO}_{2}$ oxide layer growth and secondly, the fast columnar growth of the $\mathrm{TiO}_{2}$ ejected the aluminium along the grain boundaries perpendicular to the surface, as evidence in Figure $6 \mathrm{~h}$.

Surface enrichment of vanadium, and thus the formed AgVO acicular phase, during ceramic conversion treatment may also contribute to the fast growth of the surface oxide layer. It is reported that the oxygen diffusion coefficient along grain boundary is $10^{8}$ times greater than that of bulk diffusion [31].

\subsection{Improved Tribological and Antibacterial Properties of the C3T Surface Layer}

The tribological properties of the C3T treated coupons and fixation pins are significantly improved compared with the untreated ones. With the WC ball counterpart, even under the normal load of $50 \mathrm{~N}$, or the maximum Hertzian contact pressure of $\approx 2000 \mathrm{MPa}$, for 1000 cycles, only a marginal wear track can be measured. This super wear resistance is contributed from the outermost layer structure, demonstrated in Figures 6 and 7 , which consists of agglomerates of palladium (with trace silver) oxide, vanadium oxide and amorphous-like fine grains of alumina presenting within the grain boundaries. This superficial layer with the underneath supporting nano-columnar $\mathrm{TiO}_{2}+\mathrm{Al}_{2} \mathrm{O}_{3}$ layer provided high surface hardness of above $1000 \mathrm{HV} 0.05$ and high load bearing capacity, which outperforms the poor wear resistance of the C2T treated sample under the heavy load of $50 \mathrm{~N}$ as evidence in Figure 8c, where spallation of the thin surface oxide layer and deep groves of adhesive and abrasive wear can be seen. The excellent wear performance of the treated fixation pins further proved that the C3T treatment is well suited for complexly shaped components and the loading forces, as post-drilling testing SEM observation revealed no surface damage along the body of the pins, and very minor wear at the tip of the pins (Figure 10c).

Within the biomedical field, implant-associated infections are a major concern. Therefore, the ability of a material to demonstrate antibacterial behaviour is important for reducing implant failure rates in order to reduce both patient and NHS stress. The antibacterial properties of the C2T compared with untreated Ti64 (Figure 11) demonstrated a significant reduction, of approximately $50 \%$, in the amount of $S$. aureus CFU per $\mathrm{ml}$. This is 
consistent with the literature [12,32]. This is thought to be due to titanium oxide inherently being able to produce reactive oxygen species (ROS), capable of disrupting cell membranes and walls.

A further reduction in the number of CFU per $\mathrm{ml}$ was found with C3T. Where compared with Unt, there was a $93 \%$ reduction, and when compared with $\mathrm{C} 2 \mathrm{~T}$, an $85 \%$ reduction. This is since it has silver present on the surface, which is well known for its antimicrobial activity. This is thought to be from hindering metabolism and DNA replication of the bacterial cells, ultimately resulting in cell death. [13,14,32,33]

These findings provide evidence that the reported treatments can produce a durable surface, capable of reducing the number of $\mathrm{CFU} / \mathrm{mL}$ of $\mathrm{S}$. aureus without the need for additional antimicrobial coatings/material, such as biomimetic anchored polymer brushes [34] or antimicrobial Ag/polyacrylonitrile nanofibers [35], which although they offer antibacterial activity, would not offer a durable antimicrobial solution for orthopaedic implants. To this end, further testing with different bacterial strains is merited.

\section{Conclusions}

A novel catalytic ceramic conversion treatment on Ti-6Al-4V was designed and optimised to produce a surface layer with excellent tribological and antibacterial properties for biomedical applications. The C3T was carried out by applying thin catalytic films of silver and palladium onto the Ti64 surface and then oxidising at $660{ }^{\circ} \mathrm{C}$ for a variety of hours. XRD, SEM, TEM and EDX analysis revealed a surface layer structure consisting of two sublayers: (1) a superficial layer with agglomerates of palladium (with trace silver) oxide, vanadium oxide, and amorphous-like fine grains of alumina presenting within the grain boundaries; (2) a dominant nano-columnar $\mathrm{TiO}_{2} / \mathrm{Al}_{2} \mathrm{O}_{3}$ layer with traces of silver and palladium particles. The PdAg catalytic effect on the growth of the surface oxide layer has been shown to significantly increase the oxide thickness. When treated for less than or more than $60 \mathrm{~h}$ it is 25 or 6 times faster, respectively, than that of the C2T treatments within the same treatment duration.

Surface hardness of C3T treated coupons increased from C2T of $\approx 900$ to C3T of $\approx 1100$ HV0.025. Excellent tribological performances were also observed for C3T treated coupons compared with both untreated and $\mathrm{C} 2 \mathrm{~T}$, with a reduction of wear factors from $\approx 390$ to $\approx 5 \mathrm{~m}^{3} / \mathrm{N} \cdot \mathrm{m}$. The drilling tests of the fixation pins proved the resilience of the C3T treatment for complex shaped components and forces. It is observed that the mean insertion force of the C3T pins is nearly four times lower than that of the untreated pins. Additionally, a significant reduction in the number of colony-forming units per $\mathrm{ml}$ of Staphylococcus aureus on the C3T surfaces was observed.

Author Contributions: Conceptualization, methodology, supervision H.D. (Hanshan Dong), X.L., D.B., S.L.S., S.K.; investigation, formal analysis, data curation, X.L., J.A., X.T., H.D. (Huan Dong), A.A.H., Z.Z.; writing — original draft preparation and review and editing, J.A., X.L., H.D. (Huan Dong), A.A.H. and H.D. (Hanshan Dong); funding acquisition, H.D. (Hanshan Dong), H.D. (Huan Dong). All authors have read and agreed to the published version of the manuscript.

Funding: This research was partially funded by the UK Engineering and Physical Sciences Research Council (EPSRC), grant reference EP/L016206/1.

Institutional Review Board Statement: Not applicable.

Informed Consent Statement: Not applicable.

Data Availability Statement: Data available in a publicly accessible repository.

Acknowledgments: The one of the authors, Huan Dong, would like to thank the Research Development Fund (MDS1151130) from the College of Medical and Dental Science, the University of Birmingham, UK.

Conflicts of Interest: The authors declare no conflict of interest. 


\section{References}

1. Leyens, C.; Peters, M. Titanium and Titanium Alloys: Fundamentals and Applications; Wiley: Hoboken, NJ, USA, 2006. [CrossRef]

2. Plecko, M.; Sievert, C.; Andermatt, D.; Frigg, R.; Kronen, P.; Klein, K.; Stübinger, S.; Nuss, K.; Bürki, A.; Ferguson, S.; et al. Osseointegration and biocompatibility of different metal implants-A comparative experimental investigation in sheep. BMC Musculoskelet. Disord. 2012, 13, 32. [CrossRef] [PubMed]

3. Ratner, B.D.; Hoffman, A.S.; Schoen, F.J.; Lemons, J.E. Biomaterials Science: An Introduction to Materials in Medicine, 3rd ed.; Elsevier: Amsterdam, The Netherlands, 2013.

4. Panagiotidou, A.; Cobb, T.; Meswania, J.; Skinner, J.; Hart, A.; Haddad, F.; Blunn, G. Effect of impact assembly on the interface deformation and fretting corrosion of modular hip tapers: An in vitro study. J. Orthop. Res. 2017, 36, 405-416. [CrossRef] [PubMed]

5. Pettersson, M.; Pettersson, J.; Molin Thorén, M.; Johansson, A. Release of titanium after insertion of dental implants with different surface characteristics-An ex vivo animal study. Acta Biomater. Odontol. Scand. 2017, 3, 63-73. [CrossRef] [PubMed]

6. Jamil, M.; Rafique, S.; Khan, A.M.; Hegab, H.; Mia, M.; Gupta, M.K.; Song, Q. Comprehensive analysis on orthopedic drilling: A state-of-the-art review. Proc. Inst. Mech. Eng. Part H: J. Eng. Med. 2020, 234, 537-561. [CrossRef]

7. Khan, M.; Williams, R.; Williams, D. In-vitro corrosion and wear of titanium alloys in the biological environment. Biomaterials 1996, 17, 2117-2126. [CrossRef]

8. Wen, M.; Wen, C.; Hodgson, P.; Li, Y. Improvement of the biomedical properties of titanium using SMAT and thermal oxidation. Colloids Surf. B Biointerfaces 2014, 116, 658-665. [CrossRef]

9. D BIANCO, P.; Ducheyne, P.; Cuckler, J.M. Systemic titanium levels in rabbits with a titanium implant in the absence of wear. J. Mater. Sci. Mater. Med. 1997, 8, 525-529. [CrossRef]

10. Urban, R.M.; Jacobs, J.J.; Tomlinson, M.J.; Gavrilovic, J.; Black, J.; Peoc'H, M. Dissemination of Wear Particles to the Liver, Spleen, and Abdominal Lymph Nodes of Patients with Hip or Knee Replacement*. J. Bone Jt. Surg.-Am. Vol. 2000, 82, 457-477. [CrossRef]

11. Dong, H.; Bell, T. Enhanced wear resistance of titanium surfaces by a new thermal oxidation treatment. Wear 2000, 238, 131-137. [CrossRef]

12. Dong, H.; Mukinay, T.; Li, M.; Hood, R.; Soo, S.L.; Cockshott, S.; Sammons, R.; Li, X. Improving tribological and an-ti-bacterial properties of titanium external fixation pins through surface ceramic conversion. J. Mater. Sci. Mater. Med. 2017, 28, 5. [CrossRef]

13. Romanò, C.L.; Tsuchiya, H.; Morelli, I.; Battaglia, A.G.; Drago, L. Antibacterial coating of implants: Are we missing something? Bone Jt. Res. 2019, 8, 199-206. [CrossRef]

14. Lansdown, A.B. Silver in Health Care: Antimicrobial Effects and Safety in Use. Biofunctional Text. Ski. 2006, 33, 17-34. [CrossRef]

15. Harris, L.G.; Mead, L.; Müller-Oberländer, E.; Richards, R.G. Bacteria and cell cytocompatibility studies on coated medical grade titanium surfaces. J. Biomed. Mater. Res. Part A 2006, 78A, 50-58. [CrossRef]

16. Albers, C.E.; Hofstetter, W.; Siebenrock, K.A.; Landmann, R.; Klenke, F.M. In vitro cytotoxicity of silver nanoparticles on osteoblasts and osteoclasts at antibacterial concentrations. Nanotoxicology 2013, 7, 30-36. [CrossRef]

17. Dong, H.; Bloyce, A.; Morton, P.H.; Bell, T. Surface oxidation of a titanium or titanium alloy. U.S. Patent 6210807, 3 April 2001.

18. Miles, A.A.; Misra, S.S.; Irwin, J.O. The estimation of the bactericidal power of the blood. Epidemiol. Infect. 1938, 38, 732-749. [CrossRef]

19. Van Spronsen, M.A.; Daunmu, K.; O'Connor, C.R.; Egle, T.; Kersell, H.; Oliver-Meseguer, J.; Salmeron, M.B.; Madix, R.J.; Sautet, P.; Friend, C.M. Dynamics of Surface Alloys: Rearrangement of Pd/Ag(111) Induced by CO and $\mathrm{O}_{2}$. J. Phys. Chem. C 2019, 123, 8312-8323. [CrossRef]

20. Skriver, H.L.; Rosengaard, N.M. Surface energy and work function of elemental metals. Phys. Rev. B 1992, 46, 7157-7168. [CrossRef]

21. Burnett, P.; Rickerby, D. The scratch adhesion test: An elastic-plastic indentation analysis. Thin Solid Film. 1988, 157, 233-254. [CrossRef]

22. Ding, H.; Fridrici, V.; Guillonneau, G.; Sao-Joao, S.; Geringer, J.; Fontaine, J.; Kapsa, P. Investigation on mechanical properties of tribofilm formed on Ti-6Al-4V surface sliding against a DLC coating by nano-indentation and mi-cro-pillar compression techniques. Wear 2019, 432, 202954. [CrossRef]

23. Obadele, B.A.; Andrews, A.; Shongwe, M.B.; Olubambi, P.A. Tribocorrosion behaviours of AISI 310 and AISI 316 austen-itic stainless steels in 3.5\% NaCl solution. Mater. Chem. Phys. 2016, 171, 239-246. [CrossRef]

24. Zhang, Y.; Yin, X.-Y.; Yan, F.-Y. Tribocorrosion behaviour of type S31254 steel in seawater: Identification of corrosion-wear components and effect of potential. Mater. Chem. Phys. 2016, 179, 273-281. [CrossRef]

25. Prodromides, A.E.; Scheuerlein, C.; Taborelli, M. Lowering the activation temperature of TiZrV non-evaporable getter films. Vacuum 2001, 60, 35-41. [CrossRef]

26. Shamsuddin, M. Physical Chemistry of Metallurgical Processes; Springer Nature: Berlin/Heidelberg, Germany, 2020.

27. Adochite, R.; Munteanu, D.; Torrell, M.; Cunha, L.; Alves, E.; Barradas, N.; Cavaleiro, A.; Riviere, J.; Le Bourhis, E.; Eyidi, D. The influence of annealing treatments on the properties of Ag: TiO2 nanocomposite films prepared by magnetron sputtering. Appl. Surf. Sci. 2012, 258, 4028-4034. [CrossRef]

28. Armelao, L.; Barreca, D.; Bottaro, G.; Gasparotto, A.; Maccato, C.; Tondello, E.; Lebedev, O.I.; Turner, S.; Van Tendeloo, G.; Sada, C.; et al. Rational Design of Ag/TiO2 Nanosystems by a Combined RF-Sputtering/Sol-Gel Approach. ChemPhysChem 2009, 10, 3249-3259. [CrossRef] 
29. Du, H.; Datta, P.; Lewis, D.; Burnell-Gray, J. Air oxidation behaviour of Ti6Al4V alloy between 650 and $850^{\circ}$. Corros. Sci. 1994, 36, 631-642. [CrossRef]

30. Guleryuz, H.; Cimenoglu, H. Oxidation of Ti-6Al-4V alloy. J. Alloy. Compd. 2009, 472, 241-246. [CrossRef]

31. Godlewski, J.; Gros, J.; Lambertin, M.; Wadier, J.; Weidinger, H. Raman Spectroscopy Study of the Tetrago-nal-to-monoclinic Transition in Zirconium Oxide Scales and Determination of Overall Oxygen Diffusion by Nuclear Microanalysis of $\mathrm{O}^{18}$. In Proceedings of the Zirconium in the Nuclear Industry: Ninth International Symposium, Kobe, Japan, November 1991.

32. Jiang, X.; Lv, B.; Wang, Y.; Shen, Q.; Wang, X. Bactericidal mechanisms and effector targets of $\mathrm{TiO}_{2}$ and $\mathrm{Ag}^{-\mathrm{TiO}} \mathrm{O}_{2}$ against Staphylococcus aureus. J. Med Microbiol. 2017, 66, 440-446. [CrossRef]

33. Gunputh, U.F.; Le, H.; Lawton, K.; Besinis, A.; Tredwin, C.; Handy, R.D. Antibacterial properties of silver nanoparticles grown in situ and anchored to titanium dioxide nanotubes on titanium implant against Staphylococcus aureus. Nanotoxicology 2020, 14, 97-110. [CrossRef]

34. Yang, W.J.; Cai, T.; Neoh, K.-G.; Kang, E.-T.; Dickinson, G.H.; Teo, S.L.-M.; Rittschof, D. Biomimetic anchors for antifouling and antibacterial polymer brushes on stainless steel. Langmuir 2011, 27, 7065-7076. [CrossRef]

35. Shi, Q.; Vitchuli, N.; Nowak, J.; Caldwell, J.M.; Breidt, F.; Bourham, M.; Zhang, X.; McCord, M. Durable antibacterial $\mathrm{Ag}$ / polyacrylonitrile (Ag/PAN) hybrid nanofibers prepared by atmospheric plasma treatment and electrospinning. Eur. Polym. J. 2011, 47, 1402-1409. [CrossRef] 